\title{
Does foreign direct investment promote growth? Exploring the role of financial markets on linkages ${ }^{\hbar}$
}

\author{
Laura Alfaro $^{\text {a,b,* }}$, Areendam Chanda ${ }^{c}$, Sebnem Kalemli-Ozcan ${ }^{\text {b,d }}$, Selin Sayek ${ }^{\text {e }}$ \\ a Harvard Business School, 263 Morgan Hall, Boston, MA 02163, United States \\ b NBER, 1050 Massachusetts Avenue, Cambridge, MA 02138, United States \\ c Louisiana State University, Baton Rouge, LA 70803, United States \\ ${ }^{\mathrm{d}}$ University of Houston, 4800 Calhoun Road, Houston, TX 77004, United States \\ e Bilkent University, TR-06800 Bilkent, Ankara, Turkey
}

\section{A R T I C L E I N F O}

\section{Article history:}

Received 23 June 2008

Received in revised form 19 May 2009

Accepted 24 September 2009

\section{JEL classification:}

F23

F36

F43

040

Keywords:

FDI spillovers

Backward linkages

Financial development

Economic growth

\begin{abstract}
A B S T R A C T
Do multinational companies generate positive externalities for the host country? The evidence so far is mixed varying from beneficial to detrimental effects of foreign direct investment (FDI) on growth, with many studies that find no effect. In order to provide an explanation for this empirical ambiguity, we formalize a mechanism that emphasizes the role of local financial markets in enabling FDI to promote growth through backward linkages. Using realistic parameter values, we quantify the response of growth to FDI and show that an increase in the share of FDI leads to higher additional growth in financially developed economies relative to financially under-developed ones.
\end{abstract}

(c) 2009 Elsevier B.V. All rights reserved.

\section{Introduction}

Within policy circles, there is a widespread belief that foreign direct investment (FDI) enhances the productivity of host countries and promotes economic development. This notion stems from the fact that FDI may not only provide direct capital financing but also create positive externalities via the adoption of foreign technology and know-how. Yet, the empirical evidence on the existence of such positive productivity externalities is sobering. ${ }^{1}$

The macro empirical literature finds weak support for an exogenous positive effect of FDI on economic growth. Findings in this literature indicate that a country's capacity to take advantage of FDI externalities might be limited by local conditions, such as the development of local financial markets or the educational level of the

\footnotetext{
is An earlier version of this paper circulated under the title "FDI Spillovers, Financial Markets and Economic Development."

* Corresponding author. Harvard Business School, 263 Morgan Hall, Boston, MA 02163, United States. Tel.: +1 6174957981.

E-mail address: lalfaro@hbs.edu (L. Alfaro).

${ }^{1}$ See Blomstrom and Kokko (1998), Gorg and Greenway (2004), Lipsey (2002), Barba Navaretti and Venables (2004), and Alfaro and Rodriguez-Clare (2004) for surveys of findings.
}

country, i.e., absorptive capacities. Borensztein, De Gregorio, and Lee (1998) show that the technology FDI brings translates into higher growth only when the host country has a minimum threshold of stock of human capital. Alfaro, Chanda, Kalemli-Ozcan and Sayek (2004) provide evidence that only countries with well-developed financial markets gain significantly from FDI in terms of their growth rates.

In terms of the micro empirical evidence, most of the studies using firm level panel data find no effect of foreign presence or they find negative productivity spillover effects from multinational enterprises (MNEs) to the developing country firms. ${ }^{2}$ Positive spillover effects are found only for developed countries. ${ }^{3}$ Based on these negative results, a new generation of studies argues that since multinationals would like to prevent information leakage to potential local competitors, but would benefit from knowledge spillovers to their local suppliers, FDI spillovers

\footnotetext{
2 See Aitken and Harrison (1999). An earlier generation of papers, starting with the pioneering work of Caves (1974), focused on country case studies and industry level cross sectional studies. These studies found a positive correlation between the productivity of a multinational enterprise and average value added per worker of the domestic firms within the same sector.

${ }^{3}$ Haskel, Pereira and Slaughter (2002), for example, find positive spillovers from foreign to local firms in a panel data set of firms in the U.K.; Gorg and Strobl (2002) find that foreign presence reduces exit and encourages entry by domestically owned firms in the high-tech sector in Ireland.
} 
ought to be between different industries. Hence, one must look for vertical (inter-industry) externalities instead of horizontal (intraindustry) externalities. This means the externalities from FDI will manifest themselves through forward or backward linkages, i.e., contacts between domestic suppliers of intermediate inputs and their multinational clients in downstream sectors (backward linkage) or between foreign suppliers of intermediate inputs and their domestic clients in upstream sectors (forward linkage). ${ }^{4}$ Javorcik (2004) and Alfaro and Rodriguez-Clare (2004), for example, find evidence for the existence of backward linkages between the downstream suppliers and MNEs in Lithuania; and Venezuela, Chile, and Brazil, respectively. Paralleling the macro evidence, Villegas-Sanchez (2009), using firm level data from Mexico, shows that domestic firms only enjoy productivity increases from FDI if they are located in financially developed regions. She further shows that domestic firms located in regions where access the credit is more problematic will experience a negative spillover effect from FDI.

The purpose of this study is twofold. First, in a theoretical framework, we formalize one mechanism through which FDI may lead to a higher growth rate in the host country via backward linkages, which is consistent with the micro evidence found by the recent-generation studies described above. The mechanism depends on the extent of the development of the local financial sector. This channel is also consistent with the macro literature cited above that shows the importance of absorptive capacities. ${ }^{5}$ We are not aware of any other study that is consistent with both micro and macro empirical evidence. In the second half of the paper, using realistic parameter values, we use the model to quantitatively gauge how the response of growth to FDI varies with the level of development of the financial markets. To the best of our knowledge, the paper is unique in this respect.

Our model is a small open economy characterized by two layers of industries. The downstream industry involves the production of a final consumption good by combining two intermediary goods/ production processes, which are distinguished by their ownership domestic or foreign (multinationals). These production processes, which are competitive, in turn, combine skilled labor, unskilled labor, and a range of differentiated inputs to produce their output. The latter differentiated inputs which form the second upstream industry layer are characterized by monopolistic competition. As with product variety endogenous growth models, the rate of expansion in the range of intermediates is the driver of economic growth. ${ }^{6}$

To operate a firm in the intermediate input sector, entrepreneurs must develop a new variety of intermediate input, a task that requires upfront capital investments. The more developed the local financial markets, the easier it is for credit constrained entrepreneurs to start their own firms. The increase in the number of varieties of intermediate inputs leads to positive spillovers to the intermediary processes that constitute the final good sector. As a result, financial market development allows backward linkages between foreign and domestic firms to turn into FDI spillovers. ${ }^{7}$ Our model also implies the existence of horizontal spillovers in the final goods sector since the greater

\footnotetext{
${ }^{4}$ Hirschman (1958) argues that the linkage effects are realized when one industry may facilitate the development of another by easing conditions of production, thereby setting the pace for further rapid industrialization. He also argues that in the absence of linkages, foreign investments could have limited or even negative effects in an economy (the so-called enclave economies).

5 See Alfaro, Chanda, Kalemli-Ozcan and Sayek (2004) and Harrison and McMillian (2003) for descriptions of various interactions between financial markets and foreign and domestic firms.

${ }^{6}$ The setup in our model-a final good produced by two production processes which in turn use other factors of production-is not uncommon. For example, Acemoglu (1998) has a similar setup where the final good is produced by two production processes - one skill-intensive and another unskilled intensive which in turn use a range of intermediate inputs. Markusen and Venables (1999) and Rodríguez-Clare (1996) adopt similar structures also in a FDI context.

In our model, linkages are associated with pecuniary externalities in the production of inputs. In contrast to knowledge spillovers, pecuniary externalities take place through market transactions.
}

availability of intermediate inputs not only benefits the foreign firms but also raises the total factor productivity of the domestic firms in the final goods sector, thus creating a horizontal spillover as an indirect result of the backward linkage (e.g. Merlevede and Schoors, 2007).

In our model, however, increases in foreign presence (proxied either by higher share of foreign firms in the economy or higher firm specific productivity of the existing ones), will also lead to a reallocation of resources away from domestic firms to the foreign firms. Therefore, the instantaneous effect will be a decline in domestic firms' share in final output. Assuming that foreign owned firms have higher firm specific productivity, the long run growth rate will be higher. ${ }^{8}$ In the long run, both domestic and foreign firms will benefit from the higher growth rate. However, in the short-run, the horizontal spillovers in the final goods sector, which indirectly result from the backward linkages between the foreign firm and the intermediate goods sector, exist only for the surviving domestic firms. Thus our setup can shed light on why empirical studies fail to find evidence of positive horizontal spillovers for developing countries and even find negative spillovers in some cases.

Instead of these changes in the relevant market size for foreign and domestic firms, there can also be a crowding out effect, where foreign firms aggravate the existing credit constraints and cause domestic firms to exit. Indeed, Harrison and McMillian (2003) find that in the Ivory Coast for the period 1974-1987, borrowing by foreign firms aggravated domestic firms' credit constraints. However, Harrison et al. (2004) found that foreign investors tended to "crowd in" domestic enterprises. Harrison and Rodriguez-Clare (forthcoming) argue that these contrasting results point to the policy complementarities such as complementarities with financial markets.

We then use the model to provide benchmark estimates on the effects of FDI on growth. We find that, a) holding the extent of foreign presence constant, financially well-developed economies experience growth rates that are almost twice those of economies with poor financial markets, b) increases in the share of FDI or the relative productivity of the foreign firm leads to higher additional growth in financially developed economies compared to those observed in financially under-developed economies, and finally, c) growth effects are larger when goods produced by domestic firms and MNEs are substitutes rather than complements. The exercise highlights the importance of local conditions such as market structure and human capital, the so-called absorptive capacities, for generating the positive effect of FDI on growth. By varying the relative skill endowmentswhile assuming that MNEs use skilled labor more intensively-we obtain results consistent with Borensztein, De Gregorio, and Lee (1998) who highlight the critical role of human capital.

The recent evidence from the work of Javorcik and Spatareanu (2005), among others, supports both our assumptions and findings. Their survey evidence reveals that one of the reasons multinationals in the Czech Republic, for example, do not source higher percentage of inputs domestically is the fact that local firms lack funding for investment necessary to become suppliers. ${ }^{9}$ Javorcik and Spatareanu (2007) take one step forward and examine, using data from the Czech Republic, the relation between a firm's liquidity constraints and its supply linkages with multinational corporations. The empirical analysis indicates that Czech firms supplying MNEs are less credit constrained than nonsuppliers. A closer inspection of the timing of the effect, however, suggest that this result is due to less constrained firms self-selecting into becoming MNE suppliers rather that benefits derived from the supplying relationship. Their findings suggest that well developed financial markets may be needed in order to take full advantage of the benefits associated

\footnotetext{
${ }^{8}$ This is the standard market size effect that leads to higher growth rates in endogenous growth models. Since foreign firms have a productivity advantage, increasing their share raises the marginal product of the intermediate inputs. This increasing the latters' profitability and encourages the introduction of more varieties of intermediates.

${ }^{9}$ They found that multinationals source on average $48.3 \%$ of inputs from Czech enterprises.
} 
with FDI inflows. Indeed, their results indicate that in the absence of well functioning credit markets, local firms may find it difficult to start business relationships with MNEs and thus may not be able to reap the benefits of productivity spillovers that such relationships bring. ${ }^{10}$

The importance of well-functioning financial institutions in augmenting technological innovation and capital accumulation, fostering entrepreneurial activity and hence economic development has been recognized and extensively discussed in the literature. ${ }^{11}$ Furthermore, as McKinnon (1973) stated, the development of capital markets is "necessary and sufficient" to foster the "adoption of bestpractice technologies and learning by doing." In other words, limited access to credit markets restricts entrepreneurial development. In this paper, we extend this view and argue that the lack of development of the local financial markets can limit the economy's ability to take advantage of potential FDI spillovers in a theoretical framework, a premise which is already supported by the empirical evidence.

Before moving to the model, it is worth comparing our model to the ones in FDI and the growth literatures. To the best of our knowledge, neither literature looked at the role played by financial markets for the effects of FDI on growth. Theoretical models of FDI spillovers via backward linkages include Rodríguez-Clare (1996) and Markusen and Venables (1999). These are static models and do not focus on dynamic effects of FDI spillovers. Our paper focuses on the growth aspects of these linkages between the foreign and local buyers of intermediate inputs, where these linkages interact with financial markets in a certain way. This is the main contribution of the paper. Our model closely follows Grossman and Helpman's $(1990,1991)$ small open economy setup of endogenous technological progress resulting from product innovation via increasing intermediate product diversity. We modify their basic framework to incorporate foreign owned firms and financial intermediation. The standard Grossman-Helpman setting is preferred since it provides the most transparent solution. Further, models of FDI such as the ones mentioned above also use the intermediate product variety structure in a static setting, thus making it a natural choice when moving to a dynamic framework. ${ }^{12}$ Our results on the importance of the financial markets also contribute to an emerging literature that emphasizes the importance of local policies and institutions for the benefits of FDI to be realized. ${ }^{13}$

The rest of the paper is organized as follows. Section 2 presents the model. Section 3 performs a calibration exercise using values for the parameters from the empirical literature. Section 4 concludes.

\section{The model}

\subsection{Households}

Consider a small open economy. The economy is populated by a continuum of infinitely lived agents of total mass 1 . Households maximize utility over their consumption of the final good,

$U_{t}=\int_{t}^{\infty} e^{-\rho(\tau-t)} \log u\left(C_{\tau}\right) d \tau$,

where $\rho$ is the time preference parameter, and $C_{\tau}$ denotes consumption of the final good at time is $\tau$. The final good, denoted by $Y_{t}$, is a

\footnotetext{
10 See also Alfaro and Rodriguez-Clare (2004).

11 See Goldsmith (1969), Greenwood and Jovanovic (1990), and King and Levine (1993), among others.

12 Recently, Aghion, Howitt, and Mayer-Foulkes (2005) have modeled technology transfers with imperfect financial markets in a Schumpeterian growth model, focusing on the role of credit constraints in impeding international technology transfers while we focus on the role of financial markets easing the credit constraints and allowing for increased linkages within an economy once FDI has taken place. Aghion, Comin, and Howitt (2006) develop a model that highlights the role of local savings in attracting and complementing foreign investment which spurs innovation and growth, which is closer to the spirit of our paper.

${ }^{13}$ Antras (2003), for example, argues that lack of adequate contract and property rights enforcement can limit the interaction between foreign and local firms only to hiring labor.
}

numeraire and is freely traded in world markets at a price $p_{t}$ which we normalize to 1 . The total expenditure on consumption is thus given by $E_{\tau}=p_{\tau} C_{\tau}=C_{\tau}$. Households maximize utility subject to the following intertemporal budget constraint,

$\int_{t}^{\infty} e^{-r(\tau-t)} E_{\tau} d \tau \leq \int_{t}^{\infty} e^{-r(\tau-t)} w_{\tau} d \tau+A_{t}$,

where $A_{t}$ denotes the value of the assets held by the household at time $t$, and $w_{\tau}$ is the wage income. The intertemporal budget constraint requires that the present value of the expenditures, $E_{\tau}$, not exceed the present value of labor income plus the value of asset holdings in the initial period. The solution of this standard problem implies that the value of the expenditures must grow at a rate equal to the difference between the interest rate and the discount rate. However, if this rate of growth of expenditure is different from the endogenous rate of growth of the economy then either the transversality condition is violated or the economy no longer remains a small open economy. To rule out these possibilities, we assume that households are credit constrained and can borrow at most a fixed fraction of their current income. Further, we assume that this constraint is binding, and therefore the actual rate of growth of expenditures is proportional to the rate of growth of income, $\frac{E}{E} \propto \frac{Y}{Y} \cdot{ }^{\cdot 14}$

\subsection{Production}

\subsubsection{The final goods sector}

Final good production combines two intermediary goods or production processes of domestic and foreign firms denoted respectively by $Y_{t, d}$ and $Y_{t, f}$, which are not traded. Let $p_{t, d}$ and $p_{t, f}$ denote their respective prices. The aggregate production function for this composite final good is given by,

$Y_{t}=\left[Y_{t, d}^{\rho}+\mu Y_{t, f}^{\rho}\right]^{1 / \rho}$

where $\rho \leq 1$ and $\varepsilon=1 /(1-\rho)$ represents the elasticity of substitution between $Y_{t, d}$ and $Y_{t, f}$. The market for intermediary goods/processes is competitive. We do not model the decision of foreign firms to enter the market. Therefore, the aggregator of foreign and domestic firms' production serves as an artifact that allows us to capture the interaction of foreign and domestic firms in an economy. We can exogenously vary $\mu$ to capture realistic shares of foreign and domestic firms in the final output. If $\varepsilon=\infty$, foreign and domestic firms produce perfect substitutes; $\varepsilon=-\infty$, they produce complements. If $\varepsilon=1$, the production function for the final good becomes Cobb Douglas. Thus, this aggregator allows us to consider not just the likely case where foreign and domestic firms are substitutes, but also when they are complements.

Profit maximization and competitive pricing yields a standard relative demand equation for intermediary goods,

$\frac{p_{t, f}}{p_{t, d}}=\mu\left[\frac{Y_{t, d}}{Y_{t, f}}\right]^{1-\rho}$

The cost function is given by,

$$
C\left(Y_{t}, p_{t, f}, p_{t, d}\right)=Y_{t}\left[p_{t, d}^{1-\varepsilon}+\mu^{\varepsilon} p_{t, f}^{1-\varepsilon}\right]^{\frac{1}{1-\varepsilon}}
$$

Setting the price equal to marginal cost allows us to derive an expression between the price of the domestic firm and foreign firm intermediary goods,

$p_{d}=\left(1-\mu^{\varepsilon} p_{f}^{1-\varepsilon}\right)^{\frac{1}{1-\varepsilon}}$.

\footnotetext{
14 This is only an assumption of convenience since, as we will see later, the entrepreneurs are also credit constrained and we would rather treat both groups the same to rule out any gains from arbitrage.
} 


\subsubsection{Foreign and domestic firms production processes}

Both foreign and domestic firms' production processes combine unskilled labor, skilled labor, and a range of intermediate inputs. Unskilled and skilled labor are not traded and available in fixed quantities $L$ and $H$, correspondingly. Competition in the labor market ensures that unskilled and skilled wages, $w_{t, u}$ and $w_{t, s}$, are equal to their respective marginal products.

The domestic production process is characterized by,

$Y_{t, d}=A_{d} L_{t, d}^{\beta_{d}} H_{t, d}^{\gamma_{d}} I_{t, d}^{\lambda}$

with $0<\beta_{d}<1,0<\gamma_{d}<1,0<\lambda<1$ and $\beta_{d}+\gamma_{d}+\lambda=1 . L_{t, d}, H_{t, d}$, and $I_{t, d}$ denote, respectively, the amount of unskilled labor, skilled labor, and the composite of intermediate inputs used in domestic production at any instant in time, and $A_{d}$ represents the time invariant productivity parameter.

Foreign firms use the following Cobb Douglas production function,

$Y_{t, f}=\frac{A_{f}}{\phi} L_{t, f}^{\beta_{f}} H_{t, f}^{\gamma_{f}} I_{t, f}^{\lambda}$,

with $0<\beta_{f}<1,0<\gamma_{f}<1$, and $\beta_{f}+\gamma_{f}+\lambda=1$ Like before, $L_{t, f}, H_{t, f}$ and $I_{t, f}$ denote, respectively, the amount of unskilled labor, skilled labor, and the composite intermediate input used in the foreign intermediate production process at any instant in time, and $A_{f}$ represents the time invariant productivity parameter. ${ }^{15}$

We assume that foreigners directly produce in the country rather than license the technology. The industrial organization literature suggests that firms engage in FDI not because of differences in the cost of capital but because certain assets are worth more under foreign than local control. If lower cost of capital were the only advantage a foreign firm had over domestic firms, it would still remain unexplained why a foreign investor would endure the troubles of operating a firm in a different political, legal, and cultural environment instead of simply making a portfolio investment. An investor's decision to acquire a foreign company or build a plant instead of simply exporting or engaging in other forms of contractual arrangements with foreign firms involves two interrelated aspects: ownership of an asset and the location to produce. ${ }^{16}$ First, a firm can possess some ownership advantage-a firm specific asset such as a patent, technology, process, or managerial or organizational know-how-that enables it to outperform local firms. And this is one of the reasons why researchers fail to find evidence of horizontal spillovers since this means that a foreign firm will seek to use this special asset to its advantage and prevent leakages of its technology. Hence, we model potential benefits from FDI as occurring via linkages and not through technology spillovers. However, we do model for the ownership of intangible assets and know-how by the MNE by allowing for a differential productivity level than domestic firms. Second, domestic factors, such as opportunities to tap into local resources, access to lowcost inputs or low-wage labor, or bypass tariffs that protect a market from imported goods can also lead to the decision to invest in a country rather than serve the foreign market through exports. We do not model the location choices of MNEs, rather we are interested in understanding the effects of an already occuring foreign investment. ${ }^{17}$ Finally, since our objective in this paper is to understand the effects of foreign production on local output and the role of financial markets,

\footnotetext{
15 See Markusen and Venables (1999) and Rodríguez-Clare (1996) for similar technology assumptions between foreign and domestic firms.

16 This approach to the theory of the multinational firm is also known as the OLI framework - ownership advantage, localization, internalization. See Dunning (1981).

17 For models that endogenize FDI decisions, see Helpman (1984), Markusen (1984), and Helpman, Melitz, and Yeaple (2004).
}

and not the decision to invest abroad, we model the frictions of doing business in the domestic economy with the parameter $\phi .^{18}$

Note that in the above setup, unskilled and skilled labor have different shares within the domestic and foreign intermediary production process, though the total labor share is assumed to be the same across both types of firms. This reflects the common observation that the share of labor tends to be around two-thirds of total factor payments while at the same time permitting different skill intensities within domestic and foreign production. A corollary of assuming the same total labor share is,

$\gamma_{f}-\gamma_{d}=\beta_{d}-\beta_{f}$

Following Ethier (1982), we assume that, for a given aggregate quantity of intermediate inputs used in the final good production, output is higher when the diversity in the set of inputs used is greater. This specification captures the productivity gains from increasing degrees of specialization in the production of final goods.

$I_{t, d}=I_{t, f}=I_{t}=\left[\int_{0}^{n} x_{t, i}^{\alpha} d i\right]^{1 / \alpha}$,

where $x_{t, i}$ is the amount of each intermediate input $i$ used in production at time $t$, and $n$ is the number of varieties available. Let $p_{i}$ denote the price of a variety $i$ of the intermediate input $x$. The CES specification imposes constant and equal elasticity of substitution (1/ $(1-\alpha)$ ) between a pair of goods. Each variety of intermediate input enters the production function identically and the marginal product of each variety is infinite when $x_{t, i}=0$. This implies that the firm will use all the intermediate inputs in the same quantity, thus $x_{t, i}=x_{t}$.

To capture the importance of proximity between suppliers and users of inputs, we assume that all varieties of intermediate inputs are non-traded. This is a common assumption used to capture transportation costs or local content requirements. ${ }^{19}$ The same results would arise if instead of the extreme assumption of non-tradability we assumed that inputs had significant transportation costs, something for which there is ample evidence. ${ }^{20}$ One could assume that there are some intermediate inputs that are tradable and others that are nontradable. In that case, our qualitative results would prevail, while the quantitative effects would be of smaller magnitude. However, we believe our assumptions are realistic. As mentioned, Javorcik and Spatareanu (2005) present survey data that suggest that multinationals are actively engaged in local sourcing in the Czech Republic. The top reasons reported for cooperating with Czech suppliers included: low prices, geographic proximity, savings on transport costs and on import duties. More generally, in many cases, countries tend to impose local content requirements to foreign firms.

Let $X_{t}=n_{t} x_{t}$ be the total input of intermediate inputs employed in production at time $t$, then we can rewrite $I_{t}=n_{t}^{\frac{1-\alpha}{\alpha}} X_{t}$. Production by domestic firms then is given by, ${ }^{21}$

$Y_{d}=A_{d} L_{d}^{\beta_{d}} H_{d}^{\gamma_{d}} X_{d}^{\lambda} n^{\frac{\lambda(1-\alpha)}{\alpha}}$,

and foreign firms,

$Y_{f}=\frac{A_{f}}{\phi} L_{f}^{\beta_{f}} H_{d}^{\gamma_{f}} X_{f}^{\lambda} n^{\frac{\lambda(1-\alpha)}{\alpha}}$.

${ }^{18}$ We allow for a broad interpretation of these barriers, as foreign firms need to bear a wide range of costs/risks of doing business abroad, including sovereign risk, taxes, and infrastructure and dealing with different institutions and cultures. We also considered an alternative scenario where MNEs receive a net price $p_{f} / \phi$ where $\phi>1$, reflecting these disadvantages, obtaining similar results.

19 See Grossman and Helpman (1990), Markusen and Venables (1999) and Rodríguez-Clare (1996).

20 See Overman, Redding and Venables (2001).

21 Since we will focus exclusively on the balanced growth path, we omit the time subscript for the rest of the paper. 
Thus, raising the varieties of intermediate inputs $n$, holding the quantity of intermediate goods constant, raises output productivity. Using the cost function and the fact that in a symmetric equilibrium all intermediate inputs are priced similarly, $p_{i}=p_{x}$, we can write the equilibrium conditions for the domestic and foreign firms respectively as,

$p_{d}=\frac{A_{d}^{-1} \beta_{d}^{-\beta_{d}} \gamma_{d}^{-\gamma_{d}}}{\lambda^{\lambda}} w_{u}^{\beta_{d}} w_{s}^{\gamma_{d}} p_{x}^{\lambda} n^{\frac{\lambda(\alpha-1)}{\alpha}}$,

$p_{f}=\frac{\phi A_{f}^{-1} \beta_{f}^{-\beta_{f}} \gamma_{f}^{-\gamma_{f}}}{\lambda^{\lambda}} w_{u}^{\beta_{f}} w_{s}^{\gamma_{f}} p_{x}^{\lambda} n^{\frac{\lambda(\alpha-1)}{\alpha}}$

\subsubsection{The upstream intermediate goods sector}

The intermediate inputs sector is characterized by monopolistic competition. There exists an infinite number of potential varieties of intermediate inputs, but only a subset of varieties is produced at any point in time as entrepreneurs are required to develop a new variety. Since the set of potential intermediate inputs is unbounded, an entrepreneur will never choose to develop an already existing variety. Therefore, variety $i$ of $x$ is produced by a single firm which then chooses the price $p_{i}$ to maximize profits. Firms take as given the price of competing intermediate inputs, the price of the processed good, and the price of the factors of production. In a symmetric equilibrium all intermediate inputs are priced similarly, $p_{i}=p_{x}$. Hence, profit maximization in every time period for each supplier of variety $i$ implies,

$\max \pi_{i}=p_{x} x_{i}-c_{x}\left(w_{u}, w_{s}, x_{i}\right) x_{i}$

where $c_{x}\left(w_{u}, w_{s}, x_{i}\right)$ represents the cost function and $x_{i}=x_{d}+x_{f}$ is the sum of the demand for the intermediate input $i$ by domestic and foreign firms respectively.

Production of intermediate inputs requires both skilled and unskilled labor according to the following specification,

$x_{i}=L_{x_{i}}^{\delta} H_{x_{i}}^{1-\delta}$.

Hence, the cost function for the monopolist is given by,

$c\left(w_{u}, w_{s}, x_{i}\right)=\delta^{-\delta}(1-\delta)^{-(1-\delta)} w_{u}^{\delta} w_{s}^{(1-\delta)} x_{i}$.

Profit maximization yields the result that each variety is priced at a constant mark-up $(1 / \alpha)$ over the marginal cost. ${ }^{22}$ Hence, the price of each intermediate input is given by,

$p_{x}=\delta^{-\delta}(1-\delta)^{-(1-\delta)} \frac{w_{u}^{\delta} w_{s}^{(1-\delta)}}{\alpha}$.

The fraction that domestic firms spend on all intermediate inputs is given by the corresponding share in the production function, $\lambda p_{d} Y_{d}$. This implies that for each intermediate input, the amount spent by domestic firms is given by $\lambda p_{d} Y_{d} / n$. Similarly, the amount that foreign firms spend on these inputs is given by $\lambda p_{f} Y_{f} / n$. The sum of amounts spent by foreign and domestic firms is the total revenue of the intermediate producer,

$p_{x} x_{i}=\frac{\lambda p_{d} Y_{d}}{n}+\frac{\lambda p_{f} Y_{f}}{n}$

\footnotetext{
22 See Helpman and Krugman (1985), chapter 6.
}

Therefore, we can write the operating profits per firm as,

$\pi_{i}=\frac{(1-\alpha)}{n}\left[\lambda p_{d} Y_{d}+\lambda p_{f} Y_{f}\right]$

What is the value of introducing new intermediate inputs and thus the value of the monopolistic firm? Let $v_{t}$ denote the present discounted value of an infinite stream of profits for a firm that supplies intermediate inputs at time $t$,

$v_{t}=\int_{t}^{\infty} e^{-r(s-t)} \pi_{s} d s$

Equity holders of the firm are entitled to the stream of future profits of the firm. They make an instantaneous return of $\left(\pi_{t}+\dot{v}\right)$, (profits and capital gain). They can also invest the same amount in a risk-free bond and receive return $r v_{t}$ (the prevailing market interest rate). Arbitrage in capital markets ensures that,

$\pi+\dot{v}=r v \Rightarrow \frac{\pi+\dot{v}}{v}=r$.

Thus, the rate of return of holding ownership shares is equal to the interest rate. $^{23}$

\subsubsection{Introduction of new varieties and financial markets}

In order to operate a firm in the upstream intermediate input sector, entrepreneurs must develop a new variety of intermediate inputs. The introduction of each new variety requires some initial capital investment according to the following specification,

$K=\frac{a(L+H)}{n^{\theta}}$

There are four key features of this startup specification. First, in contrast to Grossman and Helpman (1991), who assume that new varieties are developed with two inputs, labor and general knowledge, we opt only for one input, capital, to simplify the analysis. This simplification makes our results less dependent on the production parameters of the innovation sector. This has important advantages for our calibration exercise, as the stylized facts of the innovation and imitation processes are not well documented (and in particular for developing countries). Our central argument is that entrepreneurs face difficulties in obtaining, for example, loans to set up firms and this prevents the creation of backward linkages even under the presence of FDI. Assuming only capital is used for these setup costs then allows us to focus better on this issue. Secondly, startup capital is increasing in the size of the labor force. This assumption is incorporated to avoid scale effects in the model.

Finally, the introduction of a new variety depends on the existing stock of varieties. We introduce the parameter $\theta$ since this allows a more general production structure. A value of $\theta<0$ suggests a "fishing out" effect (increasing complexity in introducing new varieties) while a value of $\theta>0$ implies positive externalities ("standing on the shoulder of giants"). At this stage, we do not postulate an exact value of $\theta$, however as it turns out, we will require it to be less than $1 .{ }^{24}$ Finally, $a$ can be viewed as the level of efficiency in the innovation sector.

We assume that one unit of final output $(Y)$ can be costlessly converted into one unit of physical capital and thus the price of each unit of capital is the same as the price of $Y$, which in turn has already been normalized to 1 . Therefore, in the absence of credit market imperfections, the cost of introducing a new variety is the left hand side of Eq. (21). However, in the presence of imperfect credit markets,

\footnotetext{
${ }^{23}$ Note that the arbitrage condition does not contradict our assumption of credit constrained households since they can choose to lend to firms or invest in a risk-free bond.

${ }^{24}$ For more on the implications of these alternative assumptions, see Jones (1995).
} 
the initial capital investment must be financed by borrowing from domestic financial institutions. The domestic financial system intermediates resources at an additional cost, as in Edwards and Vegh (1997). This cost reflects the level of development of the domestic financial markets where lower levels of development are associated with higher costs. These manifest themselves in a higher instantaneous borrowing rate, $i$ which is greater than the lending rate, $r^{25}$ This simplification allows us to focus on the main theme of the paper: the role of financial markets in allowing FDI benefits to materialize. Thus, this assumption should be regarded as a shortcut to a more complex modelling of the financial sector. An Appendix, available upon request from the authors, shows that a cost verification approach following King and Levine (1993) can be easily embedded within this model without altering the key predictions. Therefore, the present discounted value of the stream of interest payments is,

$\int_{t}^{\infty} i a(L+H) n^{-\theta} e^{-r(s-t)} d s=\frac{i a(L+H) n^{-\theta}}{r}$

There is free entry into the innovation sector. Entrepreneurs will have an incentive to enter if $\frac{i a(L+H) n^{-\theta}}{r}<v$. However, this condition implies that the demand for capital will be infinite, which cannot be an equilibrium solution. Hence, we can rule out this condition ex-ante. If, on the other hand, $\frac{i a(L+H) n^{-\theta}}{r}>v$, entrepreneurs will have no incentive to engage in innovation. This possibility cannot be ruled out ex-ante but would lead to zero growth. Therefore, in equilibrium, if there is growth in the number of varieties it must be the case that,

$\frac{i a(L+H) n^{-\theta}}{r}=v$ iff $\dot{n}>0$.

This also implies,

$\frac{\dot{v}}{v}=-\theta \frac{\dot{n}}{n}$

i.e., more innovation reduces the value of each firm. ${ }^{26}$ Using this expression and the arbitrage condition in the capital markets, $\frac{\pi}{v}+\frac{\dot{v}}{v}=r$, we can rewrite Eq. (20) as,

$\frac{\pi}{v}-\theta \frac{\dot{n}}{n}=r$

Using firm profit Eqs. (19), (22) and (23) we obtain,

$\frac{r(1-\alpha) \lambda}{\operatorname{ian}^{1-\theta}}\left[\frac{p_{d} Y_{d}+p_{f} Y_{f}}{(L+H)}\right]-\theta \frac{\dot{n}}{n}=r$.

$\Rightarrow \frac{\dot{n}}{n}=\frac{r(1-\alpha) \lambda}{i a \theta}\left[\frac{p_{d} Y_{d}+p_{f} Y_{f}}{(L+H) n^{1-\theta}}\right]-\frac{r}{\theta}$

As is standard in this class of models, the growth rate of varieties, $\dot{\mathrm{n}} / n$, ultimately pins down the growth rate of both domestic and foreign processed output, and thus aggregate output as well. However in order to solve for a constant growth rate, we need to first show that the term in square brackets can be constant.

\subsection{General equilibrium and the balanced growth path}

We define the balanced growth path as a competitive equilibrium along which some key variables are constant. In particular, the growth

\footnotetext{
${ }^{25}$ As King and Levine (1993) mention, this wedge could reflect taxes, interest ceilings, required reserve policies, high intermediation costs due to labor regulation, or high administration costs, etc.

${ }^{26}$ We do not consider the implications of population growth as they do not seem relevant for the focus of this paper. However, footnote (27) discusses some of the results if it were included.
}

rate of aggregate $Y$, relative sector shares $\left(p_{d} Y_{d} / p_{f} Y_{f}\right)$, relative prices $\left(p_{d} / p_{f}, w_{s} / w_{u}\right)$, and relative factor allocations $\left(\frac{L_{d}}{L_{f}}, \frac{H_{d}}{H_{f}}\right)$ are all constant. To solve for these variables, we begin by substituting Eq. (17) for $p_{x}$ in Eqs. (12) and (13). Next, we define $\tilde{w}_{s}=w_{s} /\left(n^{1-\theta}\right)$ and $\tilde{w}_{u}=w_{u} /$ $\left(n^{1-\theta}\right)$. Abusing standard terminology, we will refer to these as efficiency adjusted wages. Using the efficiency unit adjusted wages, we can also rewrite (12) and (13) as

$p_{d}=\frac{A_{d}^{-1} \beta_{d}^{-\beta_{d}} \gamma_{d}^{-\gamma d}}{\lambda^{\lambda}}\left(\frac{\delta^{-\delta}(1-\delta)^{-(1-\delta)}}{\alpha}\right)^{\lambda} \tilde{w}_{u}^{\beta_{d}}+\delta \lambda \tilde{w}_{s}^{\gamma_{d}+(1-\delta) \lambda} n^{\frac{\lambda(\alpha-1)}{\alpha}} n^{(1-\theta)}$,

$p_{f}=\frac{\phi A_{f}^{-1} \beta_{f}^{-\beta_{f}} \gamma_{f}^{-\gamma_{f}}}{\lambda^{\lambda}}\left(\frac{\delta^{-\delta}(1-\delta)^{-(1-\delta)}}{\alpha}\right)^{\lambda} \tilde{w}_{u}^{\beta_{f}+\delta \lambda} \tilde{w}_{s}^{\gamma_{f}+(1-\delta) \lambda} n^{\frac{\lambda(\alpha-1)}{\alpha}} n^{(1-\theta)}$,

Since efficiency adjusted wages are constant, this implies that $p_{d} /\left(n^{\frac{\lambda(\alpha-1)}{\alpha}}+(1-\theta)\right)$ and $p_{f} /\left(n^{\frac{\lambda(\alpha-1)}{\alpha}}+(1-\theta)\right)$ are also constant. We will refer to these as $\tilde{\mathrm{p}}_{d}$ and $\tilde{\mathrm{p}}_{f}$, respectively. Thus, while individual prices themselves are not necessarily constant, relative prices are fixed. Furthermore individual prices will grow or fall at the rate,

$\frac{\dot{p}_{d}}{p_{d}}=\frac{\dot{p}_{f}}{p_{f}}=\left((1-\theta)-\frac{\lambda(1-\alpha)}{\alpha}\right) \frac{\dot{n}}{n}$

Substituting the expressions for $\tilde{\mathrm{p}}_{d}$ and $\tilde{\mathrm{p}}_{f}$ in Eq. (25) and after some rearranging, we have

$\frac{\dot{n}}{n}=\frac{r(1-\alpha) \lambda}{i a \theta}\left[\frac{\left(\tilde{p}_{d} Y_{d}+\tilde{p}_{f} Y_{f}\right) n^{\frac{\lambda(\alpha-1)}{\alpha}}}{(L+H)}\right]-\frac{r}{\theta}$

It is easy to see that, along the constant growth path sectoral real output grows at the rate,

$\frac{\dot{Y}_{d}}{Y_{d}}=\frac{\dot{Y}_{f}}{Y_{f}}=\frac{\lambda(1-\alpha)}{\alpha} \frac{\dot{n}}{n}$

Defining $\tilde{Y}_{d}=Y_{d} / n^{\frac{\lambda(1-\alpha)}{\alpha}}$ and $\tilde{Y}_{f}=Y_{f} / n^{\frac{\lambda(1-\alpha)}{\alpha}}$ which can be viewed as efficiency adjusted output, we now have the constant growth rate,

$\frac{\dot{n}}{n}=\frac{r(1-\alpha) \lambda}{i a \theta}\left[\frac{\left(\tilde{p}_{d} \tilde{Y}_{d}+\tilde{p}_{f} \tilde{Y}_{f}\right)}{(L+H)}\right]-\frac{r}{\theta}$

Finally, using Eqs. (28) and (29), one can deduce that GDP, Y, will grow at the rate $(1-\theta) \frac{\dot{n}}{n}$. Next, we show that we can solve for the growth rate of varieties. First, Eq. (4) can be rewritten as,

$\frac{\tilde{p}_{f}}{\tilde{p}_{d}}=\mu\left[\frac{\tilde{Y}_{d}}{\tilde{Y}_{f}}\right]^{1-\rho}$.

Eqs. (26) and (27) can also be expressed as,

$\tilde{p}_{d}=\frac{A_{d}^{-1} \beta_{d}^{-\beta_{d}} \gamma_{d}^{-\gamma d}}{\lambda^{\lambda}}\left(\frac{\delta^{-\delta}(1-\delta)^{-(1-\delta)}}{\alpha}\right)^{\lambda} \tilde{w}_{u}^{\beta_{d}+\delta \lambda} \tilde{w}_{s}^{\gamma_{d}+(1-\delta) \lambda}$
$\tilde{p}_{f}=\frac{\phi A_{f}^{-1} \beta_{f}^{-\beta_{f}} \gamma_{f}^{-\gamma_{f}}}{\lambda^{\lambda}}\left(\frac{\delta^{-\delta}(1-\delta)^{-(1-\delta)}}{\alpha}\right)^{\lambda} \tilde{w}_{u}^{\beta f}+\delta \lambda \tilde{w}_{s}^{\gamma_{f}+(1-\delta) \lambda}$

Equilibrium conditions in the labor market imply that the labor employed by the downstream domestic and foreign, and the upstream intermediate input production processes add up to the 
total labor supply in the economy. This implies, for skilled and unskilled labor, respectively,

$L_{d}+L_{f}+n L_{x}=L$

$H_{d}+H_{f}+n H_{x}=H$.

Using the cost functions for the domestic and foreign processes and the intermediate input sector, Shephard's Lemma, and expressing the prices, wages, and output in terms of their respective efficiency adjusted versions, we can rewrite these constraints as,

$\frac{\left(\beta_{d}+\delta \alpha \lambda\right) \tilde{p}_{d} \tilde{Y}_{d}}{\tilde{w}_{u}}+\frac{\left(\beta_{f}+\delta \alpha \lambda\right) \tilde{p}_{f} \tilde{Y}_{f}}{\tilde{w}_{u}}=L$,

$\frac{\left(\gamma_{d}+(1-\delta) \alpha \lambda\right) \tilde{p}_{d} \tilde{Y}_{d}}{\tilde{w}_{s}}+\frac{\left(\gamma_{f}+(1-\delta) \alpha \lambda\right) \tilde{p}_{f} \tilde{Y}_{f}}{\tilde{w}_{s}}=H$

Now we can solve for all the endogenous variables and derive the equilibrium balanced growth. In order to be able to solve the equilibrium growth rate of varieties, $\frac{\dot{n}}{n}$, we need to solve the set of prices $\left\{p_{d}, p_{f}, \tilde{\mathrm{W}}_{u}, \tilde{\mathrm{W}}_{s}\right\}$ and the outputs of the domestic and foreign sectors, $\left\{\tilde{Y}_{d}, \tilde{Y}_{f}\right\}$. To solve for the prices and the outputs, we use Eqs. (4), (5), (32), (33), (36) and (37). These equations can be solved in a sequential order. While we can solve for the FOCs and derive implicit relationships, because of Eq. (5), we cannot derive explicit solutions for the endogenous variables in terms of the parameters.

Our model exhibits some of the standard properties of product variety-based endogenous growth. Combining the above with Eq. (30),

$\frac{\dot{n}}{n}=\frac{r(1-\alpha) \lambda}{i a \theta}\left[\frac{\left(\tilde{p}_{d} \tilde{Y}_{d}+\tilde{p}_{f} \tilde{Y}_{f}\right)}{(L+H)}\right]-\frac{r}{\theta}$

we can see that, higher $\lambda$, which is the share of intermediate input costs in the intermediate production process, also drives up the growth rate of $n$. Obviously this is because a larger $\lambda$ implies a larger market size for intermediate inputs producers. An increase in either, $A_{f}$, or $\mu$, will lead to a reallocation of resources away from the domestic firm to the foreign firm. Therefore, the instantaneous effect will be a decline in domestic firms' share in output. In the long run, both domestic and foreign firms will benefit from the higher growth rate. However, in the short-run, the horizontal spillovers in the final goods sector, which indirectly result from the backward linkages between the foreign firm and the intermediate goods sector, exist only for the surviving domestic firms. This is an additional contribution of our setup, which can shed light on why empirical studies fail to find evidence of positive horizontal spillovers for developing countries and even find negative spillovers in some cases. ${ }^{27}$

Moving on to the role of the financial markets, one can see that the borrowing rate has a negative effect on the growth rate. It reflects the higher per unit cost of initial capital investment. The lending rate works through at least two channels-a positive and a negative one. The positive effect reflects a lower wedge between the two rates. The negative effect is more standard in that it reflects the higher opportunity cost of investing in the project and thus tends to lower the growth rate. However, a visual inspection of the above equation

\footnotetext{
27 So far, we have avoided discussion of population growth. Our main reason for doing so is to abstract from potential issues of differential fertility in the two types of population. This would further complicate the analysis by raising issues of human capital accumulation which are beyond the scope of the paper. However, if we assumed that population grew exogenously at the same rate $(l)$ across the two groups, then one can still solve for a balanced growth path with, $\dot{Y}_{d} / Y_{d}=\dot{Y}_{f} / Y_{f}=$ $\frac{\lambda(1-\alpha)}{\alpha} \frac{\dot{n}}{n}+l$ and aggregate $Y$ growing at the $(1-\theta) \frac{\dot{n}}{n}+l$. The rate of growth of prices and wages is unchanged.
}

suggests, trivially, that the net effect of an increase in $r$ will be to raise the growth rate (assuming, of course, that the growth rate is already positive). However, a third channel via which an increase in $r$ may work is by increasing $i$. This would make the overall effect of an increase in $r$ ambiguous. $^{28}$

Next, we turn to the calibration exercises, where by using empirical estimates of our parameters we quantitatively study the comparative static effects we have discussed so far.

\section{Calibration exercise}

The purpose of the calibration exercise is to study the quantitative growth effects of FDI, focusing on different levels of financial market development. We begin with a description of the parameters used in the analysis.

Financial development: We group countries based on their financial market development levels. Different measures have been used in the literature to proxy for financial market development. The broader financial market development measures, such as the monetaryaggregates as a share of GDP and the private sector credit extended by financial institutions as a share of GDP, capture the extent of financial intermediation; interest rate spreads, on the other hand, capture the cost of intermediation. Given that the spread between the lending and borrowing rates better captures the spirit of our model, we prefer it as the measure for the development of the financial markets. ${ }^{29}$ We find that the alternative measures of financial market development, such as the size of the financial market, the share of private sector credit in total banking activity, and the overhead costs are all highly correlated with interest rate spreads. Hence, different measures yield similar results. The average spread for the low financially developed (poor) countries, medium financially developed (middle income) countries and the high financially developed (rich) countries between 2000 and 2003 are $14.5 \%, 8.5 \%$, and $4.5 \%$, respectively.

Elasticity of substitution: In our model, $\rho$ relates to the elasticity of substitution between goods produced by foreign and domestic firms. Evidence regarding the appropriate choice of the elasticity of substitution parameter $\rho$ is sparse, given that such depiction of final goods production is an artifact to capture the interaction between foreign and domestic firms. The evidence that is closest to the spirit of our model is from the consumption literature that uses a constant elasticity of substitution utility function between varieties of domestic and foreign goods, or between tradable and non-tradable goods. Ruhl (2005) provides a detailed overview of the Armington elasticity, i.e., the elasticity of substitution between foreign and home goods, and finds that an appropriate value for $\rho$ is around $0.2 .^{30}$ While our benchmark analysis is based on the CES production function with $\rho=0.2$, we also undertake robustness analysis by allowing $\rho$ to vary between -0.9 and 0.9 .

The share of intermediate goods in the production of the final good $(\lambda)$ is assumed to be the same across the two production technologies. The formulation of the production technology allows setting the share of the intermediate goods equal to the share of physical capital in final goods production. Following Gollin (2002), we set this share equal to $1 / 3$. The remaining $2 / 3$ is accounted by skilled and unskilled labor. The

\footnotetext{
${ }^{28}$ If we restrict ourselves to the special case of where the aggregator is a Cobb Douglas function, we can solve explicitly for all the endogenous variables. The solutions are included in an Appendix, available upon request from the authors.

${ }^{29}$ Erosa (2001) defines the financial intermediation cost as the resources used per unit of value that is intermediated, which is the total value of financial assets owned by the financial institutions. He measures the financial intermediation cost as the spread between the lending and borrowing rates.

${ }^{30}$ A wide range of estimates are available from trade and business cycles literatures ranging between 0 and 0.5 . Ruhl (2005) argues that a model with temporary and permanent trade shocks can replicate both the low elasticity of substitution figures used by the international real business cycle studies and the high elasticity of substitution values found by the empirical trade studies. Such an encompassing model justifies a value of $\rho$ around 0.2 .
} 
remaining parameters used in the benchmark analysis are chosen such that those for the domestic firm capture the characteristics of the production technologies available in the developing countries; whereas, those for the foreign firm capture the characteristics of the production technologies available in the industrial countries.

Domestic firms: According to Weil (2004), the share of wages paid to skilled labor is $49 \%$ for the developing countries. We take this value to be that of domestic firms, suggesting that of labor's $2 / 3 \mathrm{rd}$ share in final goods production, $49 \%$ is due to skilled labor. Therefore, we set the share of skilled labor in domestic firms, $\gamma_{d}$, at $32 \%$. In parallel, the share of unskilled labor in domestic firms, $\beta_{d}$, is set at $35 \%$. For the benchmark analysis, we set the total factor productivity $A_{d}$ equal to 1 .

Foreign firms: The share of skilled and unskilled labor costs in output of the foreign firm is calculated in a similar fashion. Following Weil (2004), the share of wages paid to skilled labor is taken as $65 \%$ in industrial countries. Accordingly, the share of skilled labor in the foreign firm's production, $\gamma_{f}$, is set equal to $40 \%$. Similarly, the share of unskilled labor, $\beta_{f}$, is set equal to $27 \%$. Thus, $\gamma_{f}>\gamma_{d}{ }^{31}$ As a benchmark, the productivity of the foreign firm, $A_{f}$, is initially set to be twice that of the domestic firm following Hall and Jones (1999), who show the productivity parameter for a very large sample of non-industrial countries is around $45 \%$ of the productivity parameter of the U.S. With respect to the cost of doing business that the foreign firms face, $\phi$, our benchmark case is one where there is no such cost. However, note that an increase in the cost of doing business is equivalent to lower productivity of foreign firms. Thus, by considering variations in relative productivities, we can also infer implications for the variations in cost of doing business.

Share of foreign production: The share of foreign production to total output is not exogenous in the CES production function case and the choice of $\mu$ implicitly determines this share. As such, the benchmark value for $\mu$ is determined to allow for the matching of the relative output values to the real data. Lipsey (2002) estimates that in 1995 the share of world production due to FDI flows was at best $8 \%{ }^{32}$ Keeping this in mind, we set $\mu=0.1$ as our benchmark value since, as we shall see later, it produces a share of approximately $6 \%$.

Intermediate input sector: Based on the work of Basu (1996), the mark-up is assumed to be $10 \%$, and hence the value of the reciprocal of $(1+$ mark-up) is given by $\alpha=0.91$. Given the lack of any estimate, the share of unskilled labor in the production of the intermediate goods, $\delta$, is taken as 0.5 .

The stock of skilled and unskilled labor: $H$ and $L$, respectively, are set following Duffy, Papageorgiou, and Perez-Sebastian (2004). ${ }^{33}$ We calculate averages of their data for the low financially developed (poor) countries, medium financially developed (middle income) countries, and the high financially developed (rich) countries. Accordingly, we set the ratio of unskilled labor to skilled labor equal to 12 for the poor countries, 9 for the middle income countries, and 5 for the rich countries. To rule out the possibility of scale effects driving differences in growth rates, we assume that $H+L=1$. The shares of the two factors are allocated according to these three ratios so that they sum to 1 (e.g., for poor countries $H=0.077$ and $L=0.923$ ).

Additional parameters: The cost of introducing a new variety, $a$, is taken to be a free parameter. The model is calibrated to allow for the financially well-developed country growth rates to match the U.S. growth rate. Given the fact that the U.S. is often considered to be the

\footnotetext{
31 As Barba Navaretti and Venables (2004) note, there is ample evidence that foreign firms employ more skilled personnel than domestic firms. They also tend to be larger, more efficient, and pay higher wages.

32 Mataloni (2005) finds that foreign owned companies were responsible for $12 \%$ of GDP in Australia, 5\% in Italy, 7\% in Finland, 19\% in Hungary, and 22\% in the Czech Republic.

${ }_{33}$ The authors argue that there is an aggregation bias caused by differences in terms of efficiency units of the different types of labor. To overcome this bias, they weigh the length of education by the returns to schooling, and compute what they call "weighted" labor stock data.
}

Table 1

Parameters.

\begin{tabular}{lll}
\hline Benchmark parameters & & \\
\hline $\begin{array}{l}\text { Common parameters for three groups } \\
\alpha=0.91\end{array}$ & $r=0.05$ & $\phi=1$ \\
& & \\
$\begin{array}{l}\text { Production function parameters } \\
\beta^{d}=0.34\end{array}$ & $\beta^{f}=0.27$ & $\delta=0.5$ \\
$\gamma^{d}=0.33$ & $\gamma^{f}=0.40$ & $A^{f} / A^{d}=2$ \\
$\mu=0.1$ & $\rho=0.2$ & \\
Group specific parameters & & $L / H$ \\
High (rich) & Financial dev. & 5 \\
Medium (middle) & 0.045 & 5 \\
Low (poor) & 0.085 & \\
Robustness parameters & 0.145 & \\
\hline $\begin{array}{l}\text { Production function parameters } \\
\mu=0.2\end{array}$ & & \\
Group specific parameters & & \\
High (rich) & & \\
Medium (middle) & & \\
Low (poor) & & \\
\hline
\end{tabular}

Notes: We group countries based on their financial market development levels, using the interest rate spreads. The average spread for the low financially developed (poor) countries, medium financially developed (middle income) countries and the high financially developed (rich) countries between 2000 and 2003 are $14.5 \%, 8.5 \%$, and $4.5 \%$, respectively. In the benchmark case, all countries have the same ratio of unskilled to skilled labor equal to 5 . In the sensitivity analysis, we set the ratio of unskilled labor to skilled labor equal to 12 for the poor countries, 9 for the middle income countries, and 5 for the rich countries (taken from Duffy et al., 2004).

technological leader, one can assume that the productivity of foreign firms in the U.S. is no different than the productivity of the domestic U.S. firms, so that $A_{f} /\left(\phi A_{d}\right)=1$, to back out $a$. The U.S. growth rate of real GDP was approximately $3.5 \%$ for the period $1930-2000$. This condition and the other parameters above pin down $a=0.6$. We use the value of $a=0.75$ also in the sensitivity analysis when we allow the $\rho$ value to range between -0.9 and 0.9 .

The risk-free interest rate is assumed to be $5 \%$. Finally, the parameter capturing the ease of developing new variety of products, $\theta$, does not have any obvious real-world counterpart. Given that, we simply set it to $\theta=1-(\lambda(1-\alpha) / \alpha){ }^{34}$ Table 1 summarizes all the parameter values.

We consider two scenarios that reflect the benefits of FDI. The first scenario is an exogenous increase in the share of FDI due to increases in $\mu$. Increases in $\mu$ in the CES aggregator lead to a higher share of foreign output in GDP. This exercise answers the straightforward question: What happens to the overall growth rate of the economy if the more productive MNE's produce a higher share of output? The second scenario is where advances in innovation in the parent country are transmitted through FDI to the host country. These technological benefits of FDI are captured through the productivity parameter of the foreign firm (i.e, an increase in $A_{f}$ ). Our initial tests are based on the effects of a $15 \%$ increase in the productivity of the foreign firm relative to the domestic firm. Starting with our benchmark value of $A_{f} /$ $\phi A_{d}=2$, this would mean a new value of $A_{f} / \phi A_{d}=2.3(\phi=1$ in both cases). Later on when undertaking sensitivity tests, we consider a range of values between 1.15 and 2.6. The lower bound of 1.15 is based on Aitken and Harrison's (1999) finding that as a plant goes from being domestically owned to fully foreign owned, its productivity increases by about $10 \%$ to $16 \%$. Given there is no consensus in

\footnotetext{
34 The numerical exercise is based on a $\theta$ value that is dictated by the balanced growth path for the model. We further solve the model for alternative $\theta$ values and find that the results prevail for positive values of $\theta$.
} 
Table 2

Benchmark results.

\begin{tabular}{ccccc}
\hline$\mu$ & $\begin{array}{l}\text { Growth rate } \\
\text { high financial } \\
\text { development }\end{array}$ & $\begin{array}{l}\text { Growth rate } \\
\text { medium financial } \\
\text { development }\end{array}$ & $\begin{array}{l}\text { Growth rate } \\
\text { low financial } \\
\text { development }\end{array}$ & $\begin{array}{l}\text { Relative output } \\
\left(p^{f} Y^{f}\right) /\left(p^{d} Y^{d}+p^{f} Y^{f}\right)\end{array}$ \\
\hline 0.1 & 3.10 & 2.14 & 1.43 & 0.061 \\
0.2 & 4.36 & 3.01 & 2.04 & 0.134 \\
0.3 & 6.19 & 4.31 & 2.93 & 0.205 \\
0.4 & 8.76 & 6.12 & 4.18 & 0.269 \\
0.5 & 12.28 & 8.59 & 5.89 & 0.327 \\
0.6 & 17.01 & 11.92 & 8.20 & 0.379 \\
\hline
\end{tabular}

Notes: See Table 1 for the parameter values. Growth rates are in percent. The relative labor endowments are constant at the level of rich (high financial development) countries and $\rho=0.2$.

Table 3

Increasing foreign presence, changing $\mu$.

\begin{tabular}{lcllll}
\hline$\Delta \mu$ & $\begin{array}{l}\Delta \text { Growth } \\
\text { high } \\
\text { financial } \\
\text { development }\end{array}$ & $\begin{array}{l}\Delta \text { Growth } \\
\text { medium } \\
\text { financial } \\
\text { development }\end{array}$ & $\begin{array}{l}\Delta \text { Growth } \\
\text { low financial } \\
\text { development }\end{array}$ & $\begin{array}{l}\Delta \text { Relative } \\
\text { output } \\
\Delta\left(p^{f} Y^{f}\right) / \\
\left(p^{d} Y^{d}+p^{f} Y^{f}\right)\end{array}$ & $\begin{array}{l}\text { Percent } \\
\text { change } \\
\text { in } p^{f} Y^{f}\end{array}$ \\
\hline 0.1 to 0.2 & 1.26 & 0.87 & 0.61 & 7.3 & 203.2 \\
0.2 to 0.3 & 1.83 & 1.29 & 0.89 & 7.1 & 114.1 \\
0.3 to 0.4 & 2.57 & 1.81 & 1.25 & 6.4 & 84.8 \\
0.4 to 0.5 & 3.52 & 2.47 & 1.71 & 5.8 & 69.6 \\
0.5 to 0.6 & 4.73 & 3.33 & 2.31 & 5.2 & 59.9 \\
\hline
\end{tabular}

Notes: See Table 1 for the parameter values. All changes are in percentage points unless reported otherwise. The relative labor endowments are constant at the level of rich (high financial development) countries and $\rho=0.2$.

the empirical estimates, in our analysis, we use a wide of values thus providing a more comprehensive picture. ${ }^{35}$

Under both of these scenarios, $H / L$ ratios are held fixed for each country in the benchmark analysis. Hence, the resulting differences in the growth rates do not reflect human capital differences, rather they reflect variations in FDI. Both scenarios are studied separately for the CES and the Cobb Douglas production function cases, where the results for the CES production function case are reported in Section 1 and the Cobb Douglas production case is reported in the Appendix.

\subsection{Simulation results}

The benchmark results for the CES production function with $\rho=0.2$ (i.e. an elasticity of substitution of 1.25) are reported in Table 2 . As Table 2 indicates, when $\mu=0.1$ foreign production equals around $6.1 \%$ of total production, while, when $\mu=0.2$, the same ratio increases to around $13.4 \%$. Hence, as alluded to earlier, we use $\mu=0.1$ in most of the analysis. However, for the sake of completeness, the tables also list results for increments of 0.1 for $\mu$ until $\mu=0.6 .^{36}$

\subsubsection{Changes in relative productivities and shares of MNE}

The first scenario capturing an increase in the foreign presence is an exogenous increase in the FDI share (higher $\mu$ ). Table 2 lists the growth rates for the three different levels of financial development in addition to the amount of foreign output relative to domestic output (valued at their respective prices). In order to ease the discussion, in Table 3, we also present the results of Table 2 as changes over increments of 0.1 for $\mu$.

\footnotetext{
35 Note that our consideration of a range for $A_{f} / \phi A_{d}$ from 1.15 to 2.6 can also be implicitly used to understand the effects of variations in the cost of doing business, $\phi$, when $A_{f}=2 A_{d}$. Thus, $A_{f} / \phi A_{d}=2.6$ would correspond to $\phi=0.77$ and $A_{f} / \phi A_{d}=1.15$ to $\phi=1.74$. A value of $\phi<1$ might reflect a situation where the host country government enacts policies to attract FDI (e.g., fiscal or financial incentives, special laws to bypass cumbersome bureaucratic regulations that domestic firms are ordinarily subjected to), whereas $\phi>1$ could reflect the usual additional costs of business discussed earlier.

${ }^{36}$ We restrict our attention to $\mu \leq 0.6$ since this range covers most realistic values of foreign output shares.
}

For example, results in Table 3 show that the increase in $\mu$ from 0.1 to 0.2 corresponds to a tripling of the foreign output level. This increase in FDI also creates a 1.26 percentage point increase in the average growth rate of the financially well-developed countries, a 0.78 percentage point increase in the average growth rate of the financially medium developed countries, and a 0.61 percentage point increase in the average growth rate of the financially poorly developed countries. That is, for the same amount of increase in the share of FDI, the additional growth rates made possible in financially well developed countries are almost double those made possible in financially poorly developed countries.

These numbers may appear to be quite high and one might wonder if the 1.26 percentage point increase for developed economies is an overestimate. There are a couple of things to keep in mind. First, note that we have assumed $A_{f} / \phi A_{d}=2$ in these exercises. For financially developed economies, the actual gap between domestic and foreign producers is likely to be much lower and thus the estimate might be too high. Secondly, as $\mu$ increases, it is possible that new MNEs entering a domestic market might be of lower productivity than the first entrants. This could also potentially further reduce the productivity gap between domestic and foreign firms. Nevertheless, the differences in growth rates particularly between the medium level and the low level groups are still significantly different.

Another interesting result that emerges from Table 3 is that the change in the growth rates are higher when initial FDI participation is greater. For example, as $\mu$ increases from 0.1 to 0.2 , the additional growth for a country with poorly developed financial markets is 0.61 percentage points while going from 0.3 to 0.4 leads to an additional growth rate of 1.26 percentage points. Of course, one might wonder what actually happens to foreign output shares (which are a corollary of changes in $\mu$ but are easier to interpret). We already have seen that the movement from 0.1 to 0.2 leads to an output share increase from $6.1 \%$ to $13.4 \%$ of GDP. From the fourth column in Table 2, it is easy to see that as $\mu$ moves from 0.3 to 0.4 , foreign output share goes from $20.5 \%$ to $26.9 \%$. Thus, the increase in output share is slightly lower in the second case, while the increase in growth rate is higher.

Moving on to Table 4, we obtain similar qualitative results when the increase in the extent of foreign presence is captured through an increase in the relative productivity, $A^{f} /\left(\phi A^{d}\right)$. These results, combined with the ones from the earlier table, suggest that regardless of the source of the increase in the extent of foreign presence in the local economy, for the same magnitude of increase in foreign presence, the additional growth effects generated in the local economy are higher for the financially well developed countries than those generated in the financially medium developed countries, and these are higher than those generated in the financially poorly developed countries. However, an important difference is that the additional growth rates generated by improvements in the relative productivity of the foreign firm are quantitatively much lower than those discussed previously for the case of an increase in the share of FDI (higher $\mu$ ). For example, $15 \%$ increase in

\section{Table 4}

Increasing foreign presence via increasing MNE productivity: $A^{f} / A^{d} \uparrow$ by $15 \%$.

\begin{tabular}{cccccc}
\hline$\mu$ & $\begin{array}{l}\Delta \text { Growth } \\
\text { high financial } \\
\text { development }\end{array}$ & $\begin{array}{l}\Delta \text { Growth } \\
\text { medium } \\
\text { financial } \\
\text { development }\end{array}$ & $\begin{array}{l}\Delta \text { Growth } \\
\text { low financial } \\
\text { development }\end{array}$ & $\begin{array}{l}\Delta \text { Relative output } \\
\Delta\left(p^{f} Y^{f}\right) /\left(p^{f} Y^{f}+p^{d} Y^{d}\right)\end{array}$ & $\begin{array}{l}\text { Percent } \\
\text { change } \\
\text { in } p^{f} Y^{f}\end{array}$ \\
\hline 0.1 & 0.03 & 0.02 & 0.01 & 0.2 & 4.2 \\
0.2 & 0.09 & 0.06 & 0.04 & 0.4 & 5.0 \\
0.3 & 0.19 & 0.13 & 0.09 & 0.5 & 5.8 \\
0.4 & 0.35 & 0.24 & 0.17 & 0.7 & 6.6 \\
0.5 & 0.59 & 0.41 & 0.29 & 0.8 & 7.2 \\
0.6 & 0.94 & 0.66 & 0.46 & 0.9 & 7.8 \\
\hline
\end{tabular}

Notes: See Table 1 for the parameter values. All changes are in percentage points unles reported otherwise. The relative labor endowments are constant at the level of rich (high financial development) countries and $\rho=0.2$. A $15 \%$ increase in $A_{f} / A_{d}$ implies that this ratio increases in value from 2 to 2.3 . 
the relative productivity of the foreign firms increases the growth rate of the financially well developed countries by 0.03 percentage points, the growth rate of the financially medium developed countries by 0.02 percentage points, and the growth rate of the financially poorly developed countries by 0.01 percentage points. The higher relative productivity of the foreign firm corresponds to an only $4.2 \%$ increase in the total value of foreign production, $p_{f} Y_{f}$, and thus only a marginal increase in the share of foreign production in total production. These results hold qualitatively across alternative $\mu$ assumptions.

Obviously, one would be led to wonder why the effects are so dissimilar. An obvious resolution lies in the way that the two alternative scenarios work. Irrespective of the productivity advantage that foreign firms enjoy, an increase in $\mu$ ensures a higher share of total expenditures will be devoted to the output produced by foreign firms. The fact that $A_{f}>A_{d}$ ensures that this shift translates into a scale effect. Thus, the exercise in altering $\mu$, simply answers the question-given realistic productivity differences between domestic firms and foreign firms-what would a higher share of multinational production mean for the economy at various levels of financial development? On the other hand, for any given $\mu$, changes in $A_{f}$ relative to $A_{d}$ have effects that are slightly more "indirect" in the following sense. An increase in $A_{f} / A_{d}$ will reduce the relative price of the foreign good and thus will create a substitution away from the domestic good towards the foreign good. Thus, while the relative price goes down, the relative quantity goes up. With the elasticity of substitution being more than 1, we know that the overall effect is to increase $p_{f} Y_{f}$ relative to $p_{d} Y_{d}$. However, as the numbers in Table 4 indicate, the changes are small, and thus the overall growth effect, not surprisingly, will be small. One possibility is that the choice of $\rho=0.2$, which implies an elasticity of substitution of 1.25, has an important bearing on these magnitudes. In the next subsection, which deals with the sensitivity of our results, we explore the implications of varying this parameter.

An alternative way is to compare the elasticities of changes in growth due to changes in the parameters of the foreign production firm. For example, instead of restricting ourselves to specific increases in $\mu$ or $A_{f}$ / $A_{d}$ (which may not be strictly comparable), we could compare the subsequent simultaneous increases in the share of MNE output in total GDP and the associated increase in the growth rate. To fix ideas, consider row 1 of both Tables 3 and 4 . In the case of countries with poorly developed financial markets, following an increase in $\mu$ from 0.1 to 0.2 , we see that the rate of growth of GDP increases by 0.61 percentage points while the share of MNE output in total GDP increases by 7.3 percentage points (from $6.1 \%$ to $13.4 \%$ ). Dividing the former by the latter produces a value of 0.08 . This is equivalent to saying that for every 1 percentage point increase in the share of MNE output in GDP, the growth rate of the economy rises by 0.08 percentage point. Now consider instead an increase in $A_{f} / A_{d}$. Beginning from the benchmark (row 1 of 2), a $15 \%$ increase in $A_{f} / A_{d}$, as we have already seen, raises the growth rate for poorly financially developed countries by 0.01 percentage points. At the same time the share of foreign firm produced output in GDP increases by 0.2 percentage points. Here the elasticity is 0.05 . This suggests that following an increase in $A_{f} / A_{d}$, every 1 percentage point increase in the MNE share of output is associated with a 0.05 percentage point increase in the growth rate Thus, the elasticity measures of the effects of changes in $\mu$ and $A_{f} / A_{d}$ are much less disparate. We can also revisit the comparison between countries with well and poorly developed financial developed financial markets. In the case of the former, the elasticity measures yield values of 0.17 and 0.15 following increases in $\mu$ and $A_{f} / A_{d}$ respectively. Like our earlier findings, we still see that an increase in MNE share of output is associated with higher rates of economic growth for financially well developed economies.

Thus far, we have considered two alternative scenarios with qualitatively similar but quantitatively distinct outcomes. This leads to the next question-which one is more likely to hold in practice? The first scenario where $\mu$ increases seems to be more applicable to a "cross-section" analysis. With two countries beginning at the same
Table 5

$L / H$ varies by group.

\begin{tabular}{ccccccc}
\hline$\mu$ & $\begin{array}{l}\text { Growth rate } \\
\text { high financial } \\
\text { development }\end{array}$ & $\begin{array}{l}\text { Growth rate } \\
\text { medium } \\
\text { financial } \\
\text { development }\end{array}$ & $\begin{array}{l}\text { Growth rate } \\
\text { low financial } \\
\text { development }\end{array}$ & $\begin{array}{l}\text { Relative } \\
\text { output } \\
\text { high }\end{array}$ & $\begin{array}{l}\text { Relative } \\
\text { output } \\
\text { medium }\end{array}$ & $\begin{array}{l}\text { Relative } \\
\text { output } \\
\text { low }\end{array}$ \\
\hline 0.1 & 3.10 & 1.69 & 0.97 & 6.1 & 6.1 & 6.0 \\
0.2 & 4.35 & 2.39 & 1.40 & 13.4 & 13.3 & 13.2 \\
0.3 & 6.17 & 3.41 & 2.02 & 20.5 & 20.3 & 20.2 \\
0.4 & 8.74 & 4.85 & 2.90 & 26.9 & 26.7 & 26.6 \\
0.5 & 12.25 & 6.81 & 4.10 & 32.7 & 32.5 & 32.4 \\
\hline
\end{tabular}

Notes: See Table 1 for the parameter values. Growth rates are in percent. The relative labor endowments change together with financial development as high, medium and low; $\rho=0.2$.

MNE share (of GDP) but different levels of financial market development, it tells us what happens to the growth rate if the MNE share of GDP increases further. Alternatively, going down column (3) of Table 2 - we can ask what happens to the growth rate for different MNE shares for the same level of financial development. These are also the kind of questions that growth regressions often seek to answer. The second scenario, where $A_{f}$ increases relative to $A_{d}$, addresses a slightly different issue. It provides a framework to understand what happens as some firms shift to using a more productive technology. This for instance, would be applicable when domestic firms are acquired by multinational enterprises, which then bring their superior technology to these firms. Obviously, this also reflects greater MNE "participation," however, it does not take an increase in output share as a given but as an endogenous outcome of this change. Thus, both scenarios have their respective contributions.

\subsection{Sensitivity analysis}

Next we examine how the results change with the other parameters or "local conditions." We focus on changes in relative skill endowments across countries (varying $H / L$ ), the effects of alternative productivity gaps, and finally, varying the elasticity of substitution (by varying $\rho$ ). ${ }^{37}$

\subsubsection{Changes in labor endowments}

The above exercise kept the relative labor endowments constant across the three groups of countries in order to observe the differences solely on account of financial market development differences and changes in the share and/or productivity of foreign firms. The three groups however also differ in their relative labor endowments, as shown in the lower panel of Table 1 . When allowing for different labor endowments, Table 5 shows that the growth effects of higher FDI in the countries with well developed financial markets are three times more than the ones with the poor developed financial markets. Tables 6 and 7 present, respectively, the results when we allow for the relative labor endowments to differ among the three groups together with the changes in the share of foreign firms, and with the changes in the productivity of foreign firms.

When we compare Table 5 to Table 2, we see that the actual growth rates for countries with medium and poorly developed financial markets are now even lower. Indeed, the growth rate of the countries with low levels of financial market development is now only $0.97 \%$ compared to $1.43 \%$ earlier. Thus, the introduction of human capital variations across groups exacerbates differences in growth rates.

\footnotetext{
37 We also allow for changes in the cost of doing business $(\phi)$, which in our model has similar effects to those of a relative increase in the productivity to foreign firms. Note that although the interpretation is symmetric, the policy implications are different. One suggests that the authorities should improve the business environment to benefit more from FDI; the other that attracting more productive foreign firms relative to domestic firms, everything else being equal, implies higher growth rates.
} 
Table 6

Increasing foreign presence (changing $\mu$ ) and $L / H$ varies by group.

\begin{tabular}{|c|c|c|c|c|c|c|c|c|c|}
\hline$\Delta \mu$ & $\begin{array}{l}\Delta \text { Growth } \\
\text { high }\end{array}$ & $\begin{array}{l}\Delta \text { Growth } \\
\text { medium }\end{array}$ & $\begin{array}{l}\Delta \text { Growth } \\
\text { low }\end{array}$ & $\begin{array}{l}\Delta\left(p^{f} Y^{f}\right) /\left(p^{f} Y^{f}+p^{d} Y^{d}\right) \\
\text { high }\end{array}$ & $\begin{array}{l}\Delta\left(p^{f} Y^{f}\right) /\left(p^{f} Y^{f}+p^{d} Y^{d}\right) \\
\text { medium }\end{array}$ & $\begin{array}{l}\Delta\left(p^{f} Y^{f}\right) /\left(p^{f} Y^{f}+p^{d} Y^{d}\right) \\
\text { low }\end{array}$ & $\begin{array}{l}\% \Delta p^{f} Y^{f} \\
\text { high }\end{array}$ & $\begin{array}{l}\% \Delta p^{f} Y^{f} \\
\text { medium }\end{array}$ & $\begin{array}{l}\% \Delta p^{f} Y^{f} \\
\text { low }\end{array}$ \\
\hline $0.1-0.2$ & 1.25 & 0.70 & 0.43 & 7.3 & 7.2 & 7.2 & 203.2 & 202.5 & 202.2 \\
\hline $0.2-0.3$ & 1.83 & 1.02 & 0.62 & 7.1 & 7.0 & 6.9 & 114.1 & 113.6 & 113.4 \\
\hline $0.3-0.4$ & 2.56 & 1.43 & 0.88 & 6.4 & 6.4 & 6.4 & 84.8 & 84.4 & 84.2 \\
\hline $0.4-0.5$ & 3.51 & 1.96 & 1.20 & 5.8 & 5.8 & 5.8 & 69.6 & 69.2 & 69.1 \\
\hline
\end{tabular}

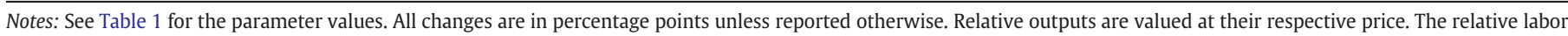
endowments change together with financial development as high, medium, low; and $\rho=0.2$.

Table 7

Increasing foreign activity via increasing MNE productivity $\left(A_{f} / A_{d} \uparrow\right.$ by $\left.15 \%\right)$, and $L / H$ varies by group.

\begin{tabular}{|c|c|c|c|c|c|c|c|c|c|}
\hline$\Delta \mu$ & $\begin{array}{l}\Delta \text { Growth } \\
\text { high }\end{array}$ & $\begin{array}{l}\Delta \text { Growth } \\
\text { medium }\end{array}$ & $\begin{array}{l}\Delta \text { Growth } \\
\text { low }\end{array}$ & $\begin{array}{l}\Delta\left(p^{f} Y^{f}\right) /\left(p^{f} Y^{f}+p^{d} Y^{d}\right) \\
\text { high }\end{array}$ & $\begin{array}{l}\Delta\left(p^{f} Y^{f}\right) /\left(p^{f} Y^{f}+p^{d} Y^{d}\right) \\
\text { medium }\end{array}$ & $\begin{array}{l}\Delta\left(p^{f} Y^{f}\right) /\left(p^{f} Y^{f}+p^{d} Y^{d}\right) \\
\text { low }\end{array}$ & $\begin{array}{l}\% \Delta p^{f} Y^{f} \\
\text { high }\end{array}$ & $\begin{array}{l}\% \Delta p^{f} Y^{f} \\
\text { medium }\end{array}$ & $\begin{array}{l}\% \Delta p^{f} Y^{f} \\
\text { low }\end{array}$ \\
\hline 0.1 & 0.03 & 0.02 & 0.01 & 0.2 & 0.2 & 0.2 & 4.23 & 4.23 & 4.22 \\
\hline 0.2 & 0.09 & 0.05 & 0.03 & 0.4 & 0.4 & 0.4 & 5.04 & 5.03 & 5.02 \\
\hline 0.3 & 0.19 & 0.10 & 0.06 & 0.5 & 0.6 & 0.6 & 5.83 & 5.81 & 5.80 \\
\hline 0.4 & 0.35 & 0.19 & 0.12 & 0.7 & 0.7 & 0.7 & 6.56 & 6.56 & 6.52 \\
\hline 0.5 & 0.59 & 0.33 & 0.20 & 0.8 & 0.8 & 0.7 & 7.21 & 7.19 & 7.18 \\
\hline
\end{tabular}

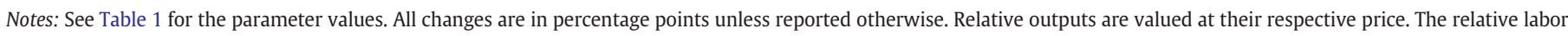
endowments change together with financial development as high, medium, low; and $\rho=0.2$.

The incremental effects of changes in $\mu$ can be inferred by comparing Tables 3 and 6. The differences in the additional growth rates are also much higher once one allows for human capital differences. When $\mu$ increases from 0.1 to 0.2 , the countries with medium level of financial development see their growth increase by 0.70 percentage points, while countries with low level of financial development see their growth increase by 0.43 percentage points. When focusing on productivity gaps, we also find that growth rate differences become larger. Comparing the results in Tables 4 and 7, one observes that when $\mu=0.2$, for example, the additional growth rate generated is 0.06 (Table 4 ) for the financially medium developed countries. When the labor endowments of these countries decrease to the actual level, the additional growth rate decreases to 0.05 (Table 7). These results imply that the 0.01 percentage points additional growth was due to the higher quality labor endowments. However, like before, productivity gaps themselves have growth effects that are of much smaller magnitude than changes in $\mu$. Overall, these results suggest that countries with more skill-intensive labor endowments benefit more in terms of growth effects from FDI, which is consistent with the empirical studies such as Borensztein et al. (1998).

\subsubsection{Alternative measures of relative productivity}

So far in the analysis, in setting the parameters regarding the relative productivity of the foreign and domestic firms, $A_{f} / \phi A_{d}$, we made use of the information from macro level studies showing that the relative productivity difference between the industrialized and developing countries is approximately 2 . Micro level studies provide further information regarding the productivity differences between foreign owned and domestic owned firms and, as we discussed above, a wide range of micro estimates are available. We report results in Table 8 panels A and B starting with the lowest value from the micro evidence, namely 1.15 (taken from Aitken and Harrison, 1999) and allow for increments of approximately $15 \%$ in this value.

Table 8

Increasing foreign productivity and presence for different relative productivity levels.

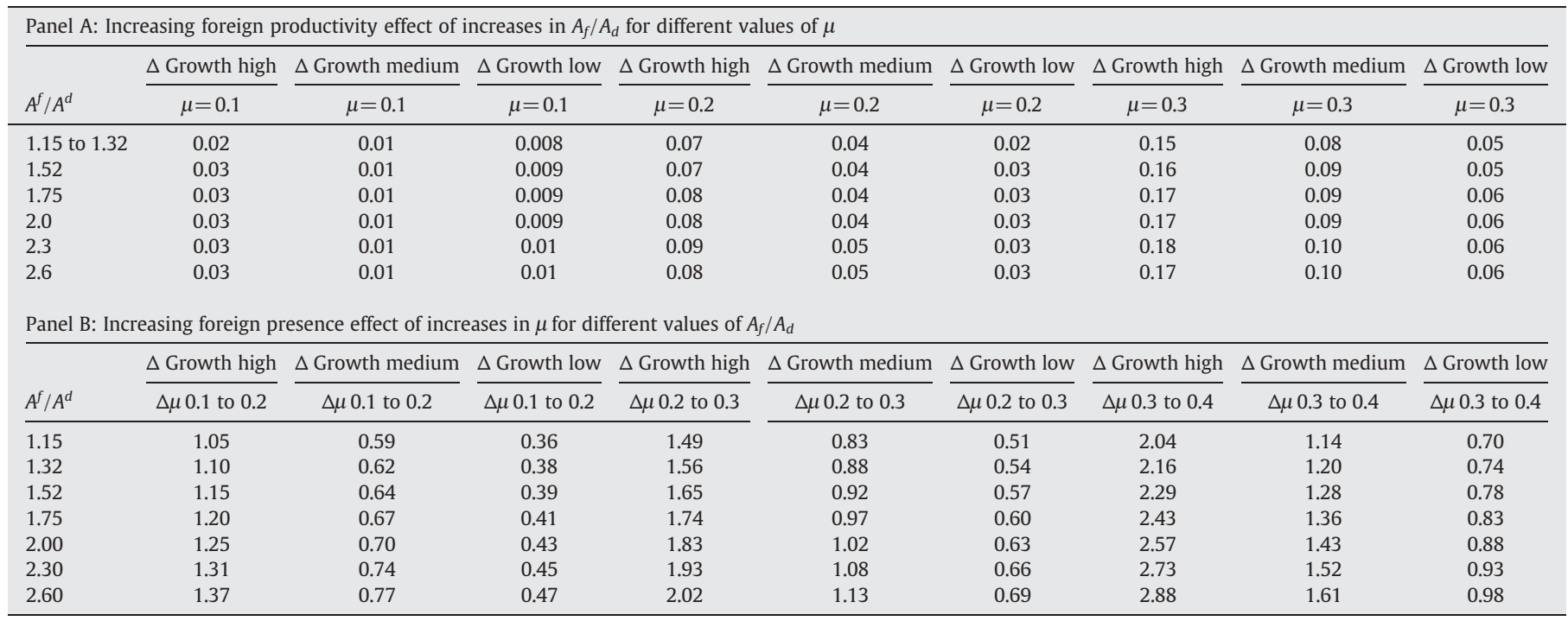

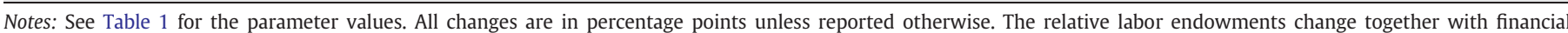
development as high, medium, low; and $\rho=0.2$. 
Table 9

MNEs and Local firms: substitutes or complements.

\begin{tabular}{|c|c|c|c|c|}
\hline$\mu$ & $\begin{array}{l}\text { Growth rate } \\
\text { high financial } \\
\text { development }\end{array}$ & $\begin{array}{l}\text { Growth rate } \\
\text { medium financial } \\
\text { development }\end{array}$ & $\begin{array}{l}\text { Growth rate } \\
\text { low financial } \\
\text { development }\end{array}$ & $\begin{array}{l}\left(p^{f} Y^{f}\right) / \\
\left(p^{f} Y^{f}+p^{d} Y^{d}\right)\end{array}$ \\
\hline \multicolumn{5}{|c|}{$\rho=-0.2$ (complements) } \\
\hline 0.1 & 1.03 & 0.67 & 0.42 & 11.74 \\
\hline 0.2 & 0.54 & 0.33 & 0.18 & 19.16 \\
\hline \multicolumn{5}{|c|}{$\rho=0.2$ (substitutes) } \\
\hline 0.1 & 3.10 & 2.13 & 1.42 & 6.10 \\
\hline 0.2 & 4.35 & 3.01 & 2.03 & 13.42 \\
\hline
\end{tabular}

Notes: See Table 1 for the parameter values. Growth rates are in percent. The relative labor endowments are constant at the level of rich (high financial development) countries.

Panel A shows the additional growth rates observed in the three groups of countries when the technology gap among the foreign and domestic firms change for different values of $\mu$ The results for the benchmark case $(\mu=0.1)$ suggest that increments of $15 \%$ increases in the technology gap between the foreign and domestic firms creates additional growth rates of 0.020 percentage points in the financially well developed countries, 0.010 percentage points in the financially medium developed countries, and 0.008 percentage points in the financially poorly developed countries. If the technology gap measure increases by $100 \%$, to 2.3 , one has to look at the cumulative of the additional growth values reported in Panel A. For the financially well developed countries, this doubling of the relative productivity measure creates an additional 0.17 percentage point growth, while creating around 0.06 percentage point growth in the financially medium developed, and around 0.05 percentage point growth in the financially poorly developed countries. Panel B alternatively looks into the additional growth rates due to increased foreign presence measured through changes in $\mu$, rather than through changes in the technology gap. The same results prevail, where the additional growth rates are almost triple for the financially well developed countries than for the financially poorly developed countries.

\subsubsection{Changes in the elasticity of substitution}

Table 9 compares the growth rates in the high, medium and low financially developed economies for $\rho=-0.2$ in the upper panel and $\rho=0.2$ in the lower panel. In particular, when the elasticity of substitution is greater than $1(\rho>0)$, for the same value of $\mu$, we observe much higher growth rates. Further increases in $\mu$ (i.e., a greater MNE presence), while leading to increases in the growth rate for $\rho=0.2$, actually reduces growth rates when $\rho=-0.2$, despite increasing MNE share in output. Thus, clearly, the elasticity of substitution in the aggregator plays a key role in our numerical exercises. These results suggest one must be cautious when talking of attracting "FDI that is complementary to local production." Such complementarity is useful when one talks of final and intermediate industry relationships. However, it does not necessarily raise the growth rates when domestic and foreign producers supply complementary final goods.

Finally, we consider the extent to which a change in the growth rate following an increase in the overall productivity gap $\left(A_{f} / \phi A_{d}\right)$ is affected by the choice of the elasticity of substitution parameter. As earlier, we consider the implications of a $15 \%$ increase in the overall productivity gap. Table 10 shows the non-monotonic relationship between $\rho$ and the additional growth rates created by increased FDI for the financially developed economies. The table depicts the relationship when $\rho>0$, i.e., the elasticity of substitution is greater than 1 and the relationship when the elasticity of substitution is less than $1(\rho<0) .{ }^{38}$ We also consider the

\footnotetext{
38 The case where $\rho=1$ is the Cobb Douglas case discussed in the next section. For values of $\rho$ in the neighborhood of 1 , there is a sharp discontinuity, and hence we do not include $\rho=1$ in the table.
}

Table 10

Different elasticities of substitution: $A_{f} / A_{d} \uparrow$ by 15 .

\begin{tabular}{|c|c|c|c|c|c|c|}
\hline \multirow[b]{2}{*}{$\rho$} & \multicolumn{3}{|l|}{$\mu=0.1$} & \multicolumn{3}{|l|}{$\mu=0.2$} \\
\hline & $\begin{array}{l}\Delta \text { Growth } \\
\text { high }\end{array}$ & $\begin{array}{l}\Delta \text { Growth } \\
\text { medium }\end{array}$ & $\begin{array}{l}\Delta \text { Growth } \\
\text { low }\end{array}$ & $\begin{array}{l}\Delta \text { Growth } \\
\text { high }\end{array}$ & $\begin{array}{l}\Delta \text { Growth } \\
\text { medium }\end{array}$ & $\begin{array}{l}\Delta \text { Growth } \\
\text { low }\end{array}$ \\
\hline 0.2 & 0.029 & 0.016 & 0.010 & 0.087 & 0.049 & 0.030 \\
\hline 0.4 & 0.012 & 0.007 & 0.004 & 0.040 & 0.022 & 0.013 \\
\hline 0.6 & 0.003 & 0.002 & 0.001 & 0.017 & 0.009 & 0.005 \\
\hline 0.8 & 0.000 & 0.000 & 0.000 & 0.002 & 0.001 & 0.000 \\
\hline-0.2 & 0.020 & 0.011 & 0.007 & 0.019 & 0.011 & 0.007 \\
\hline-0.4 & 0.029 & 0.017 & 0.010 & 0.033 & 0.019 & 0.011 \\
\hline-0.6 & 0.035 & 0.020 & 0.012 & 0.040 & 0.023 & 0.014 \\
\hline \multirow[t]{2}{*}{-0.8} & 0.040 & 0.023 & 0.014 & 0.046 & 0.026 & 0.016 \\
\hline & \multicolumn{3}{|l|}{$\mu=0.3$} & \multicolumn{3}{|l|}{$\mu=0.4$} \\
\hline$\rho$ & $\begin{array}{l}\Delta \text { Growth } \\
\text { high }\end{array}$ & $\begin{array}{l}\Delta \text { Growth } \\
\text { medium }\end{array}$ & $\begin{array}{l}\Delta \text { Growth } \\
\text { low }\end{array}$ & $\begin{array}{l}\Delta \text { Growth } \\
\text { high }\end{array}$ & $\begin{array}{l}\Delta \text { Growth } \\
\text { medium }\end{array}$ & $\begin{array}{l}\Delta \text { Growth } \\
\text { low }\end{array}$ \\
\hline 0.2 & 0.187 & 0.104 & 0.064 & 0.346 & 0.193 & 0.118 \\
\hline 0.4 & 0.081 & 0.045 & 0.027 & 0.138 & 0.076 & 0.046 \\
\hline 0.6 & 0.045 & 0.024 & 0.015 & 0.089 & 0.048 & 0.029 \\
\hline 0.8 & 0.012 & 0.006 & 0.003 & 0.047 & 0.023 & 0.013 \\
\hline-0.2 & 0.016 & 0.009 & 0.006 & 0.013 & 0.007 & 0.004 \\
\hline-0.4 & 0.032 & 0.018 & 0.011 & 0.030 & 0.017 & 0.011 \\
\hline-0.6 & 0.041 & 0.024 & 0.014 & 0.041 & 0.023 & 0.014 \\
\hline-0.8 & 0.047 & 0.027 & 0.017 & 0.048 & 0.027 & 0.017 \\
\hline
\end{tabular}

Notes: Growth rates are in percent. The relative labor endowment varies by group. The relative labor endowments change together with financial development as high, medium and low; as in Table 5. The changes in growth rates are reported as percentage point changes.

effects for various values of $\mu$. We see that as $Y_{f}$ and $Y_{d}$ become more substitutable ( $\rho$ increases), the additional growth generated actually declines. This is true for all values of $\mu$ considered here. This might initially seem counter-intuitive. However, note that when the elasticity of substitution is very high, combined with the fact that $Y_{f}$ already uses technology that is twice as productive and $\mu$ is fixed, optimal allocation would cause domestic output to have already been substituted by foreign output as much as possible. Thus, further increases in $A_{f}$ create only limited additional substitution possibilities and hence the additional growth effects are small.

In the situation where the two products are complementary (i.e., $\rho<0$ ), we see again that increases in the elasticity of substitution (i.e., as the absolute value of $\rho$ falls) leads to lower additional growth rates. However, note that the effects are actually even smaller here. The overall impression one can draw is that the introduction of a more advanced technology by the MNE while raising the growth rate, seems to be less effective when a) the products are complementary (i.e., $\rho<0$ ) and b) the products become more substitutable (i.e., higher positive values for $\rho$ ). The table furthermore shows that these results remain unchanged across alternative initial values of foreign presence in the market, i.e., for alternative values of $\mu$.

Another legitimate sensitivity analysis would be to consider the effects of asymmetric upstream intermediate input shares (i.e. $\lambda_{f} \neq \lambda_{d}$ ). For example, it is possible that multinational firms locate in a country and provide financing and specific technology to intermediate input producers but also require exclusivity contracts. A simplified way of thinking about this would be to consider the implications of $\lambda_{f}>\lambda_{d}$ in the model. Needless to mention this would reduce the extent of the spillovers. In the extreme case where $\lambda_{d}=0$ there would no spillovers. However, the growth effects of FDI would still remain and so would the effects of greater financial development on economic growth. An unfortunate implication is that depending on the elasticity of substitution, growth would be explosive or implosive. This is mainly a consequence of the fact that the foreign and domestic firms now benefit asymmetrically from technological progress. While there is only one growth rate of technology $(\dot{n} / n)$ in this economy, because of unequal intermediate shares, the sectors benefit asymmetrically. For example, consider the case where domestic and 
MNE processes are complementary (i.e. $\rho<0$ ). In this situation, even though domestic firms benefit less from technological progress and thus have lower real output growth and also lower nominal growth, they have an increasingly larger share of the economy and thus the overall growth rate of the economy is driven towards zero. This is nothing but a manifestation of the well known Baumol's Cost Disease (Baumol, 1967). With unbalanced technological progress and complementary products, the slower growing sector takes up a larger share of the economy and drives down the overall growth rate of the economy. Obviously this makes it difficult to undertake any sensible calibration and the problem is not particular to our model. $^{39}$

\section{Conclusions}

Although there is a widespread belief among policymakers that FDI generates positive productivity externalities for host countries, the empirical evidence fails to confirm this belief. In the particular case of developing countries, both the micro and macro empirical literatures consistently find either no effect of FDI on the productivity of the host country firms and/or aggregate growth or negative effects.

In this paper, we try to bridge this gap between the theoretical and the empirical literatures. The model rests on a mechanism that emphasizes the role of local financial markets in enabling FDI to promote growth through the creation of backward linkages. When financial markets are developed enough, the host country benefits from the backward linkages between the foreign and domestic firms with positive spillovers to the rest of the economy.

Our calibration exercises show that an increase in FDI leads to higher growth rates in financially developed countries compared to those observed in financially poorly developed ones. Moreover, the calibration section highlights the importance of local conditions (absorptive capacities) for the effect of FDI on economic growth. We find larger growth effects when goods produced by domestic firms and MNEs are substitutes rather than complements. Policymakers should be cautious when implementing policies aimed at attracting FDI that is complementary to local production. Desired complementarities are those between final and intermediate industry sectors; not necessarily between domestic and foreign final good produces. Finally, by varying the relative skill ratios-while assuming that MNEs use skilled labor more intensively-our results highlight the critical role of human capital in allowing growth benefits from FDI to materialize.

Some caveats are in order. We have focused on only one kind of spillover. There are likely to be additional spillovers and technology transfers. Besides, our results are based on a model that takes FDI as given. The decision of a firm to outsource or invest abroad (and the potential to generate linkages) may depend on the conditions of the country and on the characteristics of the firm. Furthermore, the possibility of imported intermediate inputs would hinder the extent of backward linkages. Future research should allow for tradability of intermediate inputs, and for differential use of alternative sources of intermediate inputs across domestic and foreign firms.

\section{Acknowledgment}

We are grateful to the participants at Stanford Institute for Theoretical Economics Summer Workshop, 2006 NEUDC, 2006 Midwest Macroeconomic Meetings, 2006 Society of Economic Dynamics Meetings, 2006 DEGIT Conference at Hebrew University, 2006 European Economic Association Annual Congress, 2007 Econometric Society Winter Meetings, 2006 Euro-Latin Study Network on Integration and Trade (ELSNIT), 2007 Excellence Award Workshop at the Kiel Institute for the World Economy, and the 2007 ACES Annual Meeting and

\footnotetext{
${ }^{39}$ In a separate Appendix, available upon request, we have worked out the qualitative aspects of this analysis.
}

seminars at Bilkent, Oregon and Louisiana State Universities and the Central Bank of Turkey for useful comments and suggestions.

\section{Appendix A. Solving the model with a CES aggregator}

As mentioned in the text, we begin with six equations,

$$
\begin{aligned}
& \tilde{p}_{d}=\frac{A_{d}^{-1} \beta_{d}^{-\beta_{d}} \gamma_{d}^{-\gamma d}}{\lambda^{\lambda}}\left(\frac{\delta^{-\delta}(1-\delta)^{-(1-\delta)}}{\alpha}\right)^{\lambda} \tilde{w}_{u}^{\beta_{d}+\delta \lambda} \tilde{w}_{s}^{\gamma_{d}+(1-\delta) \lambda} \\
& \tilde{p}_{f}=\frac{\phi A_{f}^{-1} \beta_{f}^{-\beta_{f}} \gamma_{f}^{-\gamma_{f}}}{\lambda^{\lambda}}\left(\frac{\delta^{-\delta}(1-\delta)^{-(1-\delta)}}{\alpha}\right)^{\lambda} \tilde{w}_{u}^{\beta_{f}+\delta \lambda} \tilde{w}_{s}^{\gamma_{f}+(1-\delta) \lambda},
\end{aligned}
$$

$\frac{\tilde{p}_{f}}{\tilde{p}_{d}}=\mu\left[\frac{\tilde{Y}_{d}}{\tilde{Y}_{f}}\right]^{1-\rho}$

$\tilde{p}_{d}=\left(1-\mu^{\varepsilon} \tilde{p}_{f}^{1-\varepsilon}\right) \Rightarrow \tilde{p}_{d}=p_{d}\left(\tilde{p}_{f}\right)$,

$\frac{\left(\beta_{d}+\delta \alpha \lambda\right) \tilde{p}_{d} \tilde{Y}_{d}}{\tilde{w}_{u}}+\frac{\left(\beta_{f}+\delta \alpha \lambda\right) \tilde{p}_{f} \tilde{Y}_{f}}{\tilde{w}_{u}}=L$,

$\frac{\left(\gamma_{d}+(1-\delta) \alpha \lambda\right) \tilde{p}_{d} \tilde{Y}_{d}}{\tilde{w}_{s}}+\frac{\left(\gamma_{f}+(1-\delta) \alpha \lambda\right) \tilde{p}_{f} \tilde{Y}_{f}}{\tilde{w}_{s}}=H$.

Also, recall that the growth rate of varieties is pinned down by Eq. (30),

$\frac{\dot{n}}{n}=\frac{r(1-\alpha) \lambda}{i a \theta}\left[\frac{\left(\tilde{p}_{d} \tilde{Y}_{d}+\tilde{p}_{f} \tilde{Y}_{f}\right)}{(L+H)}\right]-\frac{r}{\theta}$

We next list the steps involved in arriving at a solution for this setup:

1) First of all note that we can use Eqs. (38) and (39) to express efficiency wages as a function of the prices of foreign and domestic goods,

$$
\begin{gathered}
\tilde{w}_{u}=A_{d u} \Delta A_{f u} \tilde{p}_{d}^{\frac{\left(\gamma_{f}+(1-\delta) \lambda\right)}{\left(\gamma_{f}-\gamma_{d}\right)}} \frac{-\left(\gamma_{d}+(1-\delta) \lambda\right)}{\left(\gamma_{f}-\gamma_{d}\right)}, \\
\tilde{p}_{f}, \\
\tilde{w}_{s}=A_{d s} \Delta A_{f s} \tilde{p}_{d}^{\frac{-\left(\beta_{f}+\delta \lambda\right)}{\left(\gamma_{f}-\gamma_{d}\right)}} \tilde{p}_{f}^{\frac{\beta_{d}+\delta \lambda}{\left(\gamma_{f}-\gamma_{d}\right)} .}
\end{gathered}
$$

where,

$$
\begin{aligned}
& A_{d u}=\left(A_{d} \beta_{d}^{\beta_{d}} \gamma_{d}^{\gamma d}\right)^{\frac{\left(\gamma_{f}+(1-\delta) \lambda\right)}{\left(\gamma_{f}-\gamma_{d}\right)}} ; \quad A_{f u}=\left(\frac{A_{f} \beta_{f}^{\beta_{f}} \gamma_{f}^{\gamma_{f}}}{\phi}\right)^{\frac{-\left(\gamma_{d}+(1-\delta) \lambda\right)}{\left(\gamma_{f}-\gamma_{d}\right)}} ; \\
& A_{d s}=\left(A_{d} \beta_{d}^{\beta_{d}} \gamma_{d}^{\gamma d}\right)^{\frac{-\left(\beta_{f}+\delta \lambda\right)}{\left(\gamma_{f}-\gamma_{d}\right)}} ; \quad A_{f s}=\left(\frac{A_{f} \beta_{f}^{\beta_{f}} \gamma_{f}^{\gamma_{f}}}{\phi}\right)^{\frac{\beta_{d}+\delta \lambda}{\left(\gamma_{f}-\gamma_{d}\right)}} ; \\
& \Delta=\left(\frac{\delta^{-\delta}(1-\delta)^{-(1-\delta)}}{\alpha}\right)^{-\lambda} .
\end{aligned}
$$

From these two Eqs. (45) and (46) we get,

$$
\begin{aligned}
& \frac{\tilde{p}_{d}}{\tilde{p}_{f}}=\frac{A_{d}^{-1} \beta_{d}^{-\beta_{d}} \gamma_{d}^{-\gamma d}}{\phi A_{f}^{-1} \beta_{f}^{-\beta_{f}} \gamma_{f s}^{-\gamma_{f}}}\left(\frac{\tilde{w}_{u}}{\tilde{w}_{s}}\right)^{\gamma_{f}-\gamma_{d}}, \\
& \frac{\tilde{p}_{d}}{\tilde{p}_{f}}=\frac{\Lambda_{f}}{\Lambda_{d}}\left(\frac{\tilde{w}_{u}}{\tilde{w}_{s}}\right)^{\gamma_{f}-\gamma_{d}} .
\end{aligned}
$$


where $\Lambda_{d}=\left(A_{d} \beta_{d}^{\beta_{d}} \gamma_{d}^{\gamma d}\right), \Lambda_{f}=\left(A_{f} \beta_{f}^{\beta_{f}} \gamma_{f}^{\gamma_{f}}\right) / \phi$. Dividing Eq. (42) by (43),

$\Rightarrow \frac{\left(\beta_{d}+\delta \alpha \lambda\right)+\left(\beta_{f}+\delta \alpha \lambda\right) \frac{\tilde{p} f \tilde{Y} f}{\tilde{p} d \tilde{Y} d}}{\left(\gamma_{d}+(1-\delta) \alpha \lambda\right)+\left(\gamma_{f}+(1-\delta) \alpha \lambda\right) \frac{\tilde{p} f \tilde{Y} f}{\tilde{p} d \tilde{Y} d}}=\frac{\tilde{w}_{u} L}{\tilde{w}_{s} H}$.

Note that the cost minimization Eq. (40) can be rewritten as,

$\left[\frac{1}{\mu} \frac{\tilde{p}_{f}}{\tilde{p}_{d}}\right] \frac{\tilde{Y}_{f}}{1-\rho}=\frac{\tilde{Y}_{d}}{\tilde{1}}$

Substituting this into the previous equations,

$\frac{\left(\beta_{d}+\delta \alpha \lambda\right)+\left(\beta_{f}+\delta \alpha \lambda\right)\left(\frac{\tilde{p} f}{\tilde{p} d}\right)^{1-\frac{1}{1-\rho}}\left[\frac{1}{\mu}\right]^{\frac{-1}{1-\rho}}}{\left(\gamma_{d}+(1-\delta) \alpha \lambda\right)+\left(\gamma_{f}+(1-\delta) \alpha \lambda\right)\left(\frac{\tilde{p} f}{\tilde{p} d}\right)^{1-\frac{1}{1-\rho}}\left[\frac{1}{\mu}\right]^{\frac{-1}{1-\rho}}}=\left(\frac{\Lambda_{d}}{\Lambda_{f}} \frac{\tilde{p}_{d}}{\tilde{p}_{f}}\right)^{\frac{1}{\gamma_{f}-\gamma_{d}}} \frac{L}{H}$

Finally using Eq. (5), $\left(1-\mu^{\varepsilon} \tilde{p}_{f}^{1-\varepsilon}\right)^{\frac{1}{1-\varepsilon}}=\tilde{p}_{d}$, we can rewrite the expression above to obtain,

$$
\begin{gathered}
\Rightarrow \frac{\left(\beta_{d}+\delta \alpha \lambda\right)+\left(\beta_{f}+\delta \alpha \lambda\right)\left(\frac{\tilde{p}_{f}}{\left(1-\mu^{\varepsilon} \tilde{p}_{f}^{1-\varepsilon}\right)^{\frac{1}{1-\varepsilon}}}\right)^{1-\frac{1}{1-\rho}}\left[\frac{1}{\mu}\right]^{\frac{-1}{1-\rho}}}{\left(\gamma_{d}+(1-\delta) \alpha \lambda\right)+\left(\gamma_{f}+(1-\delta) \alpha \lambda\right)\left(\frac{\tilde{p}_{f}}{\left(1-\mu^{\varepsilon} \tilde{p}_{f}^{1-\varepsilon}\right)^{\frac{1}{1-\varepsilon}}}\right)^{1-\frac{1}{1-\rho}}\left[\frac{1}{\mu}\right]^{\frac{-1}{1-\rho}}} \\
=\left(\frac{1}{\Lambda} \frac{\left(1-\mu^{\varepsilon} \tilde{p}_{f}^{1-\varepsilon}\right)^{\frac{1}{1-\varepsilon}}}{\tilde{p}_{f}}\right)^{\frac{1}{\gamma_{f}-\gamma_{d}}} \frac{L}{H}
\end{gathered}
$$

Thus solving for $\tilde{p}_{f}=\tilde{p}_{f}^{*}$, where $*$ denotes the solved value.

2) Given $\tilde{\mathrm{p}}_{f}$, we can again use $\tilde{p}_{d}^{*}=\left(1-\mu^{\varepsilon} \tilde{p}_{f}^{1-\varepsilon}\right)^{\frac{1}{1-\varepsilon}}$ to back out $\tilde{\mathrm{p}}_{d}$.

3) Since we now have both $\tilde{p}_{d}^{*}$ and $\tilde{p}_{f}^{*}$, we can also derive the efficiency wages and the relative outputs. To derive the efficiency wages, we can substitute prices into Eqs. (45) and (46), as to rewrite them such that we have $\tilde{\mathrm{w}}_{u}^{*}=\tilde{\mathrm{w}}_{u}^{*}\left(\tilde{p}_{d}, \tilde{p}_{f}\right)$ and $\tilde{\mathrm{w}}_{s}^{*}=\tilde{\mathrm{w}}_{s}^{*}\left(\tilde{p}_{d}, \tilde{p}_{f}\right)$. More explicitly, after some tedious rearrangements, we get,

$$
\begin{aligned}
& \tilde{w}_{u}^{*}=A_{d u} \Delta A_{f u}\left(\tilde{p}_{d}^{*}\right)^{\frac{\left(\gamma_{f}+(1-\delta) \lambda\right)}{\left(\gamma_{f}-\gamma_{d}\right)}}\left(\tilde{p}_{f}^{*}\right)^{\frac{-\left(\gamma_{d}+(1-\delta) \lambda\right)}{\left(\gamma_{f}-\gamma_{d}\right)}}, \\
& \tilde{w}_{s}^{*}=A_{d s} \Delta A_{f s}\left(\tilde{p}_{d}^{*}\right)^{\frac{-\left(\beta_{f}+\delta \lambda\right)}{\left(\gamma_{f}-\gamma_{d}\right)}}\left(\tilde{p}_{f}^{*}\right)^{\frac{\beta_{d}+\delta \lambda}{\left(\gamma_{f}-\gamma_{d}\right)},}
\end{aligned}
$$

This allows us also to derive the relative wages,

$$
\frac{\tilde{w}_{u}^{*}}{\tilde{w}_{s}^{*}}=\left(\frac{\Lambda_{d}}{\Lambda_{f}} \frac{\tilde{p}_{d}^{*}}{\tilde{p}_{f}^{*}}\right)^{\frac{1}{\gamma_{f}-\gamma_{d}}}
$$

From Eq. (40), we obtain a value for relative outputs,

$$
\Rightarrow \frac{\tilde{Y}_{f}}{\tilde{Y}_{d}}=\left[\frac{1}{\mu} \frac{\tilde{p}_{f}^{*}}{\tilde{p}_{d}^{*}}\right]^{\frac{-1}{1-\rho}} .
$$

4) We can write $\tilde{Y}_{f}=Y\left(\tilde{Y}_{d} ; \tilde{p}_{d}^{*}, \tilde{p}_{f}^{*}\right)$.

5) Taking the unskilled labor market Eq. (42),

$\left(\beta_{d}+\delta \alpha \lambda\right) \tilde{p}_{d}^{*} \tilde{Y}_{d}+\left(\beta_{f}+\delta \alpha \lambda\right) \tilde{p}_{f}^{*} \tilde{Y}_{f}=\tilde{w}_{u}^{*} L$,

6) We can now substitute this into Eq. (52) and get $\tilde{Y}_{f}^{*}$.
7) Thus, we can now derive the growth rate from Eq. (44):

$\frac{\dot{n}}{n}=\frac{r(1-\alpha) \lambda}{i \theta a}\left[\frac{\tilde{p}_{d}^{*} \tilde{Y}_{d}^{*}+\tilde{p}_{f} \tilde{Y}_{f}^{*}}{(L+H)}\right]-\frac{r}{\theta}$

Finally, all this means that the growth rate of aggregate GDP is $\frac{\dot{n}}{n}(1-\theta)$.

\section{References}

Acemoglu, D., 1998. Why do new technologies complement skills? Directed technical change and wage inequality. Quarterly Journal of Economics 113, 1055-1089.

Aghion, P., Howitt, P., Mayer-Foulkes, D., 2005. The effect of financial development on convergence: theory and evidence. Quarterly Journal of Economics 120, 173-222.

Aghion, P., Comin, D., Howitt, P., 2006. When does domestic saving matter for economic growth? NBER Working Paper 12275.

Aitken, B.J., Harrison, A., 1999. Do domestic firms benefit from direct foreign investment? Evidence from Venezuela. American Economic Review 89, 605-618.

Alfaro, L., Rodriguez-Clare, A., 2004. Multinationals and linkages: evidence from Latin America. Economia 4, 113-170.

Alfaro, L., Chanda, A., Kalemli-Ozcan, S., Sayek, S., 2004. FDI and economic growth, the role of local financial markets. Journal of International Economics 64, 113-134.

Antras, P., 2003. Firms, contracts and trade structure. Quarterly Journal of Economics $118,1374-1418$.

Barba Navaretti, G., Venables, A., 2004. Multinational Firms in the World Economy. Princeton University Press, Princeton.

Basu, S., 1996. Procyclical productivity: increasing returns or cyclical utilization. Quarterly Journal of Economics 111, 719-751.

Baumol, William J., 1967. Macroeconomics of Unbalanced Growth: The Anatomy of Urban Crisis. American Economic Review LVII, No. 3 (June 1967) pp. 415-426.

Blomstrom, M., Kokko, A., 1998. Multinational corporations and spillovers. Journal of Economic Surveys 12, 247-277.

Borensztein, E., De Gregorio, J., Lee, J.-W., 1998. How does foreign direct investment affect economic growth? Journal of International Economics 45, 115-135.

Caves, R., 1974. Multinational firms, competition and productivity in the host country. Economica 41, 176-193.

Duffy, J., Papageorgiou, C., Perez-Sebastian, F., 2004. Capital-skill complementarity? Evidence from a panel of countries. The Review of Economics and Statistics 86, 327-344.

Dunning, J.H., 1981. International Production and the Multinational Enterprise. George Allen and Unwin, London.

Edwards, S., Vegh, C., 1997. Banks and macroeconomic disturbances under predetermined exchange rates. Journal of Monetary Economics 40, 239-278.

Erosa, A., 2001. Financial intermediation and occupational choice in development. Review of Economic Dynamics 4, 303-334.

Ethier, W., 1982. National and international returns to scale in the modern theory of international trade. American Economic Review 72, 389-405.

Goldsmith, R.W., 1969. Financial Structure and Development. Yale University Press, New Haven.

Gollin, D., 2002. Getting income shares right. Journal of Political Economy 110, 458-474.

Gorg, H., Greenway, D., 2004. Much ado about nothing? Do domestic firms really benefit from foreign direct investment? World Bank Research Observer 19, 171-197.

Gorg, H., Strobl, E., 2002. Multinational companies and indigenous development: an empirical analysis. European Economic Review 46, 1305-1322.

Greenwood, J., Jovanovic, B., 1990. Financial development, growth and the distribution of income. Journal of Political Economy 98, 1076-1107.

Grossman, G., Helpman, E., 1990. Comparative advantage and long-run growth. American Economic Review 80, 796-815.

Grossman, G., Helpman, E., 1991. Innovation and Growth in the Global Economy. MIT Press, Cambridge, MA.

Hall, R.E., Jones, C., 1999. Why do some countries produce so much more output per worker than others? The Quarterly Journal of Economics 114, 83-116.

Harrison, A., McMillian, M.S., 2003. Does foreign direct investment affect domestic firms' credit constraints. Journal of International Economics 61, 73-100.

Harrison, A., McMillian, M.S., Love, I., 2004. Global Capital Flows and Financing Constraints. Journal of Development Economics 75, 269-301.

Harrison, A., Rodriguez-Clare, A., forthcoming. Trade, Foreign Investment, and Industrial Policy, Handbook of Development Economics. http://are.berkeley.edu/ harrison/HandbookFeb200911.pdf.

Haskel, J.E., Pereira, S.C., Slaughter, M.J., 2002. Does inward foreign direct investment boost the productivity of local firms? NBER Working Paper 8433.

Helpman, E., 1984. A simple theory of international trade and multinational corporations. Journal of Political Economy 92, 451-471.

Helpman, E., Krugman, P., 1985. Market Structure and Foreign Trade: Increasing Returns, Imperfect Competition, and the International Economy. MIT Press, Cambridge, MA.

Helpman, E., Melitz, M., Yeaple, S.R., 2004. Export versus FDI with heterogeneous firms. American Economic Review 94, 300-316.

Hirschman, A., 1958. The Strategy of Economic Development. Yale University Press, New Haven.

Javorcik, B.S., 2004. Does foreign direct investment increase the productivity of domestic firms? In search of spillovers through backward linkages. American Economic Review 94, 605-627. 
Javorcik, B.S., Spatareanu, M., 2005. Disentangling FDI Spillovers effects: what do firm perceptions tell us? In: Moran, T., Grahan, E., Blomstrom, M. (Eds.), Does Foreign Direct Investment Promote Development? Institute for International Economics, Washington D.C.

Javorcik, B.S., Spatareanu, M., 2007. Liquidity Constraints and Linkages with Multinationals, mimeo.

Jones, CharlesI., 1995. R \& D-based models of economic growth. The Journal of Political Economy 103, 759-784.

King, R., Levine, R., 1993. Finance, entrepreneurship and growth: theory and evidence. Journal of Monetary Economics 32, 513-542.

Lipsey, R.E., 2002. Home and host country effects of FDI. NBER Working Paper 9293.

Markusen, J., 1984. Multinationals, multi-plant economies and the gains from trade. Journal of International Economics 16, 205-226.

Markusen, J., Venables, A.J., 1999. Foreign direct investment as a catalyst for industrial development. European Economic Review 43, 335-338.
Mataloni, R.J., 2005. U.S. multinational companies: operations in 2003. Survey of Current Business 9-29 (July).

McKinnon, R., 1973. Money and Capital in Economic Development. Brookings Institute, Washington.

Merlevede, B., Schoors, K., 2007. FDI and the consequences: towards more complete capture of spillover effects. William Davidson Institute at the University of Michigan Stephen M. Ross Business School Working Paper.

Overman, H., Redding, S., Venables, A., 2001. The economic geography of trade, production and income: a survey of empirics. CEPR Discussion Paper No. 2978.

Rodríguez-Clare, A., 1996. Multinationals, linkages and economic development American Economic Review 86, 852-873.

Ruhl, K., 2005. The Elasticity Puzzle in International Economics, mimeo.

Villegas-Sanchez, C., 2009. FDI Spillovers and the Role of Local Financial Markets: Evidence from Mexico, mimeo.

Weil, D., 2004. Economic Growth. Addison-Wesley, Boston. 